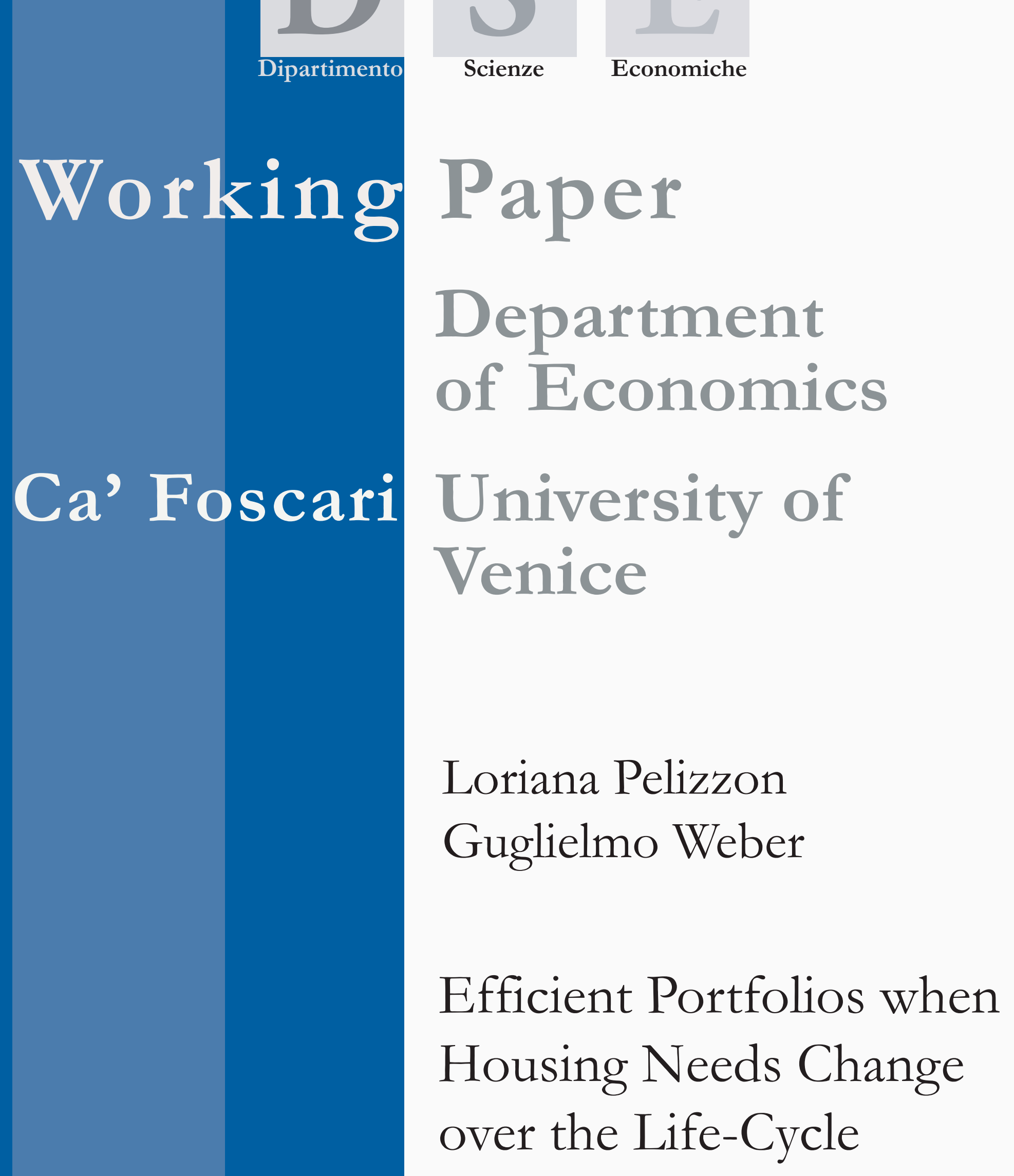




\title{
Efficient Portfolios when Housing Needs Change over the Life-Cycle
}

\author{
Loriana Pelizzon \\ University of Venice and SSAV \\ Guglielmo Weber \\ University of University of Padua, IFS and CEPR.
}

\begin{abstract}
We address the issue of the efficiency of household portfolios in the presence of housing risk. We treat housing stock as an asset and rents as a stochastic liability stream: over the life-cycle, households can be short or long in their net housing position. Efficient financial portfolios are the sum of a standard Markowitz portfolio and a housing risk hedge term that multiplies net housing wealth. Our empirical results show that net housing plays a key role in determining which household portfolios are inefficient. The largest proportion of inefficient portfolios obtains among those with positive net housing, who should invest more in stocks.
\end{abstract}

\section{Keywords}

Housing and portfolio choice, Portfolio efficiency, Rental risk, Life-cycle.

JEL Codes

D91, G11

\author{
Address for correspondence: \\ Loriana Pelizzon \\ Department of Economics \\ Ca' Foscari University of Venice \\ Cannaregio 873, Fondamenta S.Giobbe \\ 30121 Venezia - Italy \\ Phone: (++39) 0412349164 \\ Fax: (++39) 0412349176 \\ e-mail: loriana.pelizzon@unive.it
}

This Working Paper is published under the auspices of the Department of Economics of the Ca' Foscari University of Venice. Opinions expressed herein are those of the authors and not those of the Department. The Working Paper series is designed to divulge preliminary or incomplete work, circulated to favour discussion and comments. Citation of this paper should consider its provisional character.

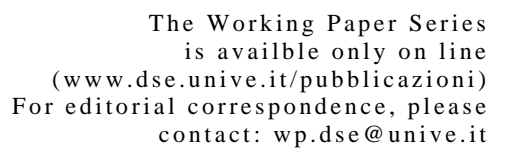

he Working Paper Series

correspondence, please
Department of Economics

Ca' Foscari University of Venice

Cannaregio 873, Fondamenta San Giobbe

30121 Venice Italy

Fax: ++390412349210 


\title{
Efficient Portfolios when Housing Needs Change over the Life-Cycle
}

\author{
by \\ Loriana Pelizzon ${ }^{*}$ \\ and \\ Guglielmo Weber $^{* *}$
}

\begin{abstract}
:
We address the issue of the efficiency of household portfolios in the presence of housing risk. We treat housing stock as an asset and rents as a stochastic liability stream: over the life-cycle, households can be short or long in their net housing position. Efficient financial portfolios are the sum of a standard Markowitz portfolio and a housing risk hedge term that multiplies net housing wealth. Our empirical results show that net housing plays a key role in determining which household portfolios are inefficient. The largest proportion of inefficient portfolios obtains among those with positive net housing, who should invest more in stocks.
\end{abstract}

JEL Classification: D91, G11

Keywords: Housing and portfolio choice, Portfolio efficiency, Rental risk, Life-cycle.

\footnotetext{
\# Acknowledgments: Paper presented at the LSE- FMG conference on "Public Policy Perspectives on Pensions Reform", London, March 2005, the CAM Workshop on "Household Choice of Consumption, Housing and Portfolio", Copenhagen, June 2005, EFA meeting, Moscow, August 2005, SIE meeting, Naples, 2005, $2^{\text {nd }}$ Csef-Igier Symposium on Economics and Institutions, C6, Naples, 2006, Gutmann Center Symposium on Real Assets and Portfolio Management, Wein, 2006, seminar at Humboldt University, Berlin, 2006 and Finance and Consumption Workshop, Madrid, 2007. We are grateful for helpful discussions with Agar Brugiavini, Alessandro Bucciol, Roberto Casarin and Stephen Schaefer, and for comments made by our discussants as well as conference participants.

${ }^{*}$ University of Venice and SSAV. Dipartimento di Scienze Economiche, University Ca' Foscari of Venice, Fondamenta San Giobbe 873, 30121 Venezia, Italy; Phone +39 041 2349164, Fax +39 041 2349176, email: loriana.pelizzon@unive.it.

${ }^{* *}$ University of Padua, IFS and CEPR. Dipartimento di Scienze Economiche, University of Padua, Via del Santo, 33, 35123 Padova, Italy; Phone +39 049 8274271, Fax +39 049 8274211, email: guglielmo.weber@unipd.it.
} 


\title{
Efficient Portfolios when Housing Needs Change over the Life- Cycle
}

\begin{abstract}
:
We address the issue of the efficiency of household portfolios in the presence of housing risk. We treat housing stock as an asset and rents as a stochastic liability stream: over the life-cycle, households can be short or long in their net housing position. Efficient financial portfolios are the sum of a standard Markowitz portfolio and a housing risk hedge term that multiplies net housing wealth. Our empirical results show that net housing plays a key role in determining which household portfolios are inefficient. The largest proportion of inefficient portfolios obtains among those with positive net housing, who should invest more in stocks.
\end{abstract}




\section{Introduction}

The role of real estate in personal portfolio management is controversial, and often neglected in the finance literature. Allowing housing wealth into total wealth in the analysis of portfolio choice raises conceptual issues: the main residence provides essential housing services, and it is less than obvious that it should be considered as wealth. Also, housing needs change with age, particularly because of demographics. Demographics drive housing needs up in the first half of the life cycle, down in the second half, very much the same way they also affect non-durable consumption (Attanasio et al, 1999). Consumers can meet their housing need in two different ways: they can rent housing services, or they can purchase housing stock. When the price of renting positively correlates with house prices, home-ownership is a way to reduce the risk related to the consumption of housing services (as argued in Sinai and Souleles, 2005).

In this paper we provide a conceptual framework in which households treat their main residence differently according to their age for the purposes of portfolio management. Elderly households should count most of their main residence as wealth, as they could liquidate it to buy different goods (medical care, long term care, and holidays), while easily meeting their likely housing needs over their remaining years by renting. Single, young households, on the other hand, would be unwise to consider their main residence as wealth, given that they are likely to trade up in the future.

The way we address the issue of optimal portfolio choice in the presence of housing risk is to explicitly treat housing stock as an asset, and rents as a stochastic liability stream (in the sense of Elton and Gruber, 1992). We derive conditions under which standard mean variance analysis holds once wealth includes the value of real estate net of the rent liability. Our wealth definition allows us to distinguish between investors who are long on housing, or "over-housed" (the value of the housing stock they own exceeds the present value of future housing services, that is they have a long net housing position) and short on housing, or "under-housed" (vice-versa, short net housing 
position). The former group is more exposed to house price risk, the latter (that includes tenants and young homeowners whose housing needs are increasing) to rent risk.

In this context we show when and how financial portfolio allocations are affected by the presence of a non-zero net housing position. We also show how one can assess the efficiency of financial portfolios when the optimal allocation is indeed affected by the presence of this term.

To do this, we develop a simple dynamic model and derive conditions under which this allows the analysis to be carried out in a static mean-variance framework. Under these conditions, we see that households should allocate financial assets with two objectives in mind: to maximize the expected return of their portfolio, given a certain risk (standard Markowitz portfolio), and to hedge the risk in their net housing position. We can test whether household portfolios are efficient conditionally on housing by computing a statistic that is based on the financial portfolio Sharpe Ratio (the ratio of the mean excess return to the standard deviation) after allowance has been made for the hedge term. In the empirical application, we derive the optimal financial portfolios for any given net housing position and ask whether household portfolios are in line with these optimal portfolios, that is whether they are efficient, given the presence of housing risk. In our model, we allow housing consumption needs to change with age, but assume that they are given to the household. To satisfy them, households can rent or own housing stock, but in both cases they bear risks, because the price of the house and the rental rate are driven by a single stochastic process that correlates with financial assets returns. This allows us to distinguish between households that have long housing positions (“over-housed") - or short positions (“under-housed").

The aim of our application is to evaluate the empirical relevance of housing risk in household portfolios. In particular, we compare the efficiency of asset allocations for households who are over-housed, under-housed or have net housing positions close to zero.

In our application, we analyze household portfolio data from the Italian 2002 Survey on Household Income and Wealth (2002). This survey is run by Bank of Italy and contains detailed information on a number of financial variables, such as self-reported values for household portfolio positions, as 
well as on the market and rental value of the main residence. It also contains records on earnings, expected or actual retirement age, occupation and pension income of each individual in the household. For each household we impute a value for human capital and for the present value of future rents, by exploiting information available in previous waves of the survey (SHIW waves from 1989 to 2000). We also use data on financial assets returns and on housing returns from other sources.

This paper is organized as follows. In the next section we present the intuition of our empirical strategy and relate it to the literature on the role of housing investment in portfolio choice (the formal dynamic model is derived in the Appendix). Section 2 describes the data and section 3 presents the empirical results. Section 4 presents robustness analysis and section 5 concludes.

\section{Analysis conditional on housing}

Standard mean-variance analysis (Tobin, 1958, Markowitz, 1952) implies that the vector of asset holdings should satisfy:

$$
\underline{X}_{0}^{*_{T}}=\left[\frac{-\frac{\partial U}{\partial F W}}{\frac{\partial^{2} U}{\partial F W^{2}}}\right] \Sigma^{-1} \underline{\mu}^{T}
$$

where FW is financial wealth, $\Sigma$ is the variance-covariance matrix of returns on $n$ risky assets, and $\mu$ is the row vector of expected excess returns (that is, returns in excess of the risk-free rate). The sum of the X's is the wealth invested in risky assets. $U(F W)$ is the utility function - in the simplest case, investors are assumed to maximize the expected utility of end-of-period wealth and returns are normally distributed.

Equation (1) can be derived in a dynamic model where all wealth is invested in liquid financial assets whose returns follow Brownian motions with time-invariant parameters (Merton, 1969). However, things may change when some assets are illiquid, and therefore are traded infrequently, such as housing. There are circumstances where the standard analysis applies even in the presence 
of illiquid real assets over those periods when these are not traded (Grossman and Laroque, 1990, Flavin and Nakagawa, 2004). But in the more general case where housing returns correlate with financial assets returns, the standard analysis fails to capture the presence of a hedge term in the optimal portfolio (Damgaard, Fuglsbjerg and Munk, 2003).

In the vast literature on efficient portfolios, only a few papers incorporate real estate as an asset. Goetzmann and Ibbotson (1990) and Goetzmann (1993) use regression estimates of real estate price appreciation, and Ross and Zisler (1991) calculate returns from real estate investment trust funds, to characterize the risk and return to the real estate investment. Flavin and Yamashita (2002) use data from the 1968-1992 waves of the Panel Study of Income Dynamics that contain records on the owner's estimated value of the house and compute rates of return from regional real estate price data. Flavin and Yamashita characterize the efficiency frontier for house owners, when the house cannot be changed in the short run and there are non-negativity constraints on all assets. They consider the case where financial returns are not correlated with housing returns, and therefore the main effect of housing is to change the background risk faced by investors. Pelizzon and Weber (2006) extend Flavin and Yamashita to cover the case of non-zero correlation between housing and financial asset returns, but concentrate on home-owners and do not take rent-risk into account. Finally, in a model with short-selling constraints, fixed costs of stock market participation and where the mortgage cannot exceed a fraction of the housing stock owned, Cocco (2005) finds that investment in housing can explain the variability of stockholdings in household portfolios, and in particular limited participation among younger and poorer households.

In this paper, we analyze a model where consumers maximize a value function that is the sum of life-time utility of non-durable and durable consumption and a bequest function that depends on total bequeathed wealth, subject to the standard intertemporal constraints. We treat consumption of durable goods services as exogenously determined ("housing needs"), and allow households to either purchase or rent the necessary housing stock (as Sinai and Souleles, 2005, and Yao and Zhang, 2005). We also allow for age-specific survival probabilities, and assume that there is unitary 
(or anyhow constant) correlation between the housing stock return and the rental rate of housing services (this assumption is also made by Yao and Zhang, 2005). All asset returns (including the housing return) follow Brownian motions, and they correlate with each other. Human capital is instead assumed to be a risk-free investment (or it has non-systematic risk - see Bodie, Merton and Samuelson, 1992).

In this context, we argue that the relevant notion of housing wealth is the difference between housing stock owned and the present value of current and future rents. Typically, this position is negative for young households who are likely to trade up in the housing market, it is positive for old households, whose housing needs are decreasing and are instead interested in the liquidation value of the house because they wish to trade down (as stressed in Banks et al., 2004) or have a bequest motive. In this model, home-ownership provides insurance against rent risk (see Sinai and Souleles, 2005). Rents are a stochastic liability stream, similarly to pension payments for pension funds (Elton and Gruber, 1992, and Campbell and Viceira, 2005)

In this model (that is presented and developed more formally in the Appendix), if households have non-zero positions in housing (that is, if their home is worth more or less than the present value of their future housing needs), and if financial returns have non-negative correlations with housing returns, the standard analysis is no longer valid.

In fact, we can show that in our model, when owning is a perfect hedge against rent risk, efficient portfolios satisfy the following relation:

$$
\underline{X}_{0}^{* T}=\left[\frac{-\frac{\partial J}{\partial T W}}{\frac{\partial^{2} J}{\partial T W^{2}}}\right] \Sigma^{-1} \underline{\mu^{T}}-P_{0} D_{0} \Sigma^{-1} \Gamma_{b P}^{T}
$$

where:

- $\quad T W$ denotes total wealth (the sum of financial wealth, FW, human capital, HC, and the value of the home, $\mathrm{H}$, net of debt and of the present value of future rents). 
- $\quad P_{0} D_{0}$ is defined as the difference between the value of the home, $\mathrm{H}$, and the present value of future rents (housing needs). Households are long on housing (over-housed) if $P_{0} D_{0}$ is positive (they have more housing stock than is implied by their consumption requirements), are short on housing (under-housed) otherwise (this includes people who rent their home, or whose current home is inadequate considering their future needs).

- $\Sigma$ is the variance-covariance matrix of returns on risky financial assets, and $\mu$ is the vector of expected excess returns (that is, returns in excess of the risk-free rate).

- $\quad \Gamma_{b p}$ denotes the (row) vector of covariances between the return on housing and on risky financial assets.

- $J$ is the value function of the intertemporal optimization problem.

Equation (2) reveals that the optimal portfolio is the sum of a standard Markowitz portfolio and a hedge term (see also Mayers, 1973, and Anderson and Danthine, 1981). The former is multiplied by the inverse of absolute risk aversion, whereas the latter is not. This implies that risk-averse investors should hedge housing return risk in exactly the same way, for a given net housing position.

In the sequel of the paper we shall show the importance of the net housing position as defined here. Gross housing wealth apparently accounts for the largest portion of the sum of financial and real wealth, but this does not take into account the future rents liability, that is overall of comparable magnitude as housing wealth, even though it differs greatly across households.

Mean-variance efficiency is usually assessed on the basis of a graphical comparison. The efficient frontier is drawn in the expected return-standard deviation space, and single portfolios are also represented in this space.

In Figure 1 we show how our analysis can be interpreted graphically. The broken line is the meanvariance frontier for financial assets (housing is not included). The dark dots represent two household portfolios, one of which, A, clearly efficient according to equation (1) (it lies on the efficient frontier), the other, B, probably inefficient (it lies well below). However, these conclusions 
are incorrect if the households have non-zero net housing wealth. In fact, equation (2) implies that efficiency should be evaluated once the hedge term is taken out of the portfolio.

Figure 1. The effects of net housing wealth on portfolio efficiency

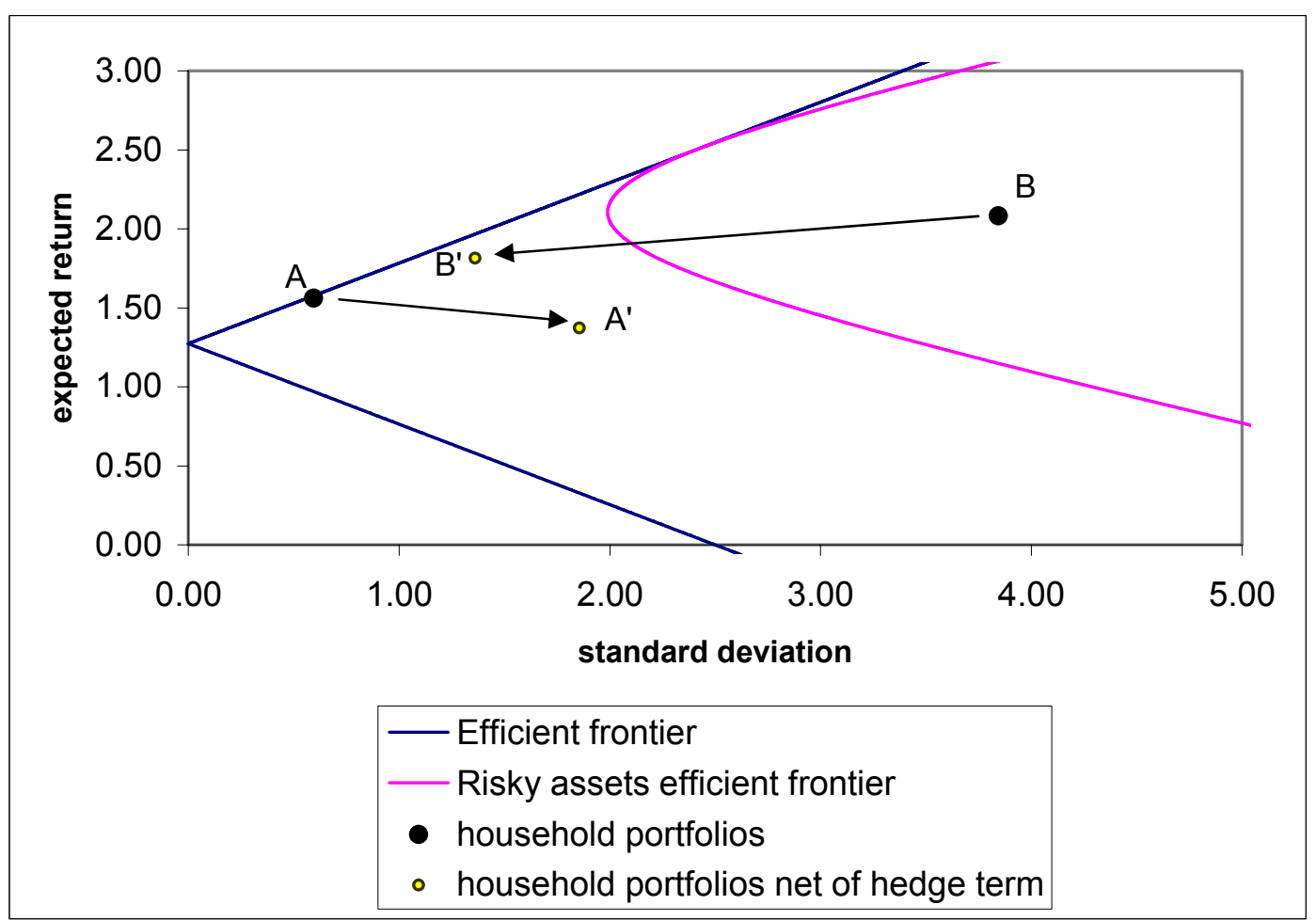

In our graphical example this is shown by the arrows. The resulting portfolios (indicated by circles) look quite different now: the first household portfolio, which apparently lied on the efficient frontier, now appears inefficient, $\mathbf{A}^{\prime}$, whereas the reverse is true for the second household portfolio, B'. The economic interpretation of these two cases is simple: the first household closely follows the standard Markowitz rules, but fails to hedge housing risk. The second household instead correctly hedges housing risk, but the resulting portfolio appears inefficient when the standard approach is taken.

Graphical comparisons are extremely useful, but do not take into account that the efficiency frontier is not known, rather it is estimated (and the same applies to the mean-variance performance of any given portfolio). To assess whether a portfolio is indeed efficient we need to take into account this source of variability, that is we need to use a formal statistical test. Jobson and Korkie $(1982,1989)$ 
and Gibbons, Ross and Shanken (1989) have proposed a test of the significance of the difference between the actual portfolio held by an investor and a corresponding efficient portfolio. This test is based on the difference between the slopes of arrays from the origin through the two portfolios in the expected return-standard deviation space. If the actual portfolio is an efficient portfolio, the two slopes will be the same; if the actual portfolio is inefficient, the slope of the efficient portfolio will be significantly greater. These slopes are of course the Sharpe ratios, which relate directly to expected utility, as shown in Gourieroux and Monfort (2003).

We can test whether household portfolios are efficient conditionally on housing by computing a statistic that is based on the financial portfolio Sharpe Ratio after allowance has been made for the hedge term. In fact, Gourieroux and Jouneau (1999) derive an efficiency test for the conditional or constrained case, i.e. for the case where a subset of asset holdings is potentially constrained (housing in our case). They define the Sharpe ratio of the unconstrained risky financial assets portfolio as:

$$
S_{1}=\underline{\mu} \Sigma^{-1} \underline{\mu}^{T}
$$

The Sharpe ratio for the observed (constrained) portfolio made of the first $n$ (financial) assets is defined in this notation as:

(4) $\quad S_{1}(Z)=\frac{\left[\mu v_{1}^{T}\right]^{2}}{v_{1} \Sigma v_{1}^{T}}$

where $v_{1}^{T}=\underline{X}_{0}^{T}+P_{0} D_{0} \Sigma^{-1} \Gamma_{b P}^{T}$ (see equation 2), that is the actual risky financial asset portfolio after eliminating the hedge term and $Z^{T} \equiv\left(\begin{array}{c}X_{0}^{T} \\ P_{0} D_{0}\end{array}\right)$.

When all asset returns are normally distributed, Gourieroux and Jouneau show that the Wald statistic:

$$
\xi_{1}=T \frac{\hat{S}_{1}-\hat{S}_{1}(Z)}{1+\hat{S}_{1}(Z) \frac{Z \Omega Z^{T}}{v_{1} \Sigma v_{1}^{T}}}
$$


is distributed as a $\chi^{2}(n-1)$ under the null hypothesis that the risky financial assets portfolio (after eliminating the hedge term) lies on the financial efficient frontier ${ }^{1}$ where:

(6) $\Omega=\left(\begin{array}{cc}\Sigma & \Gamma_{b P}^{T} \\ \Gamma_{b P} & \sigma_{P}^{2}\end{array}\right)$

where $\sigma_{P}^{2}$ is the variance of excess returns on housing.

Gourieroux and Jouneau also show that a test for the efficiency of the whole portfolio can be derived as a special case by setting $v_{1}=Z$. In this special case, this test is asymptotically equivalent to the test derived by Jobson and Korkie $(1982,1989)$ and Gibbons, Ross and Shanken (1989).

The intuition behind the test is the following. The standard test for portfolio efficiency is based on (the square of) the Sharpe ratio. The Sharpe ratio is in fact the same along the whole efficient frontier (with the exception of the intercept), that is along the capital market line. This test breaks down when one asset is taken as given, because the efficient frontier in the mean-variance space corresponding to all assets is no longer a line, rather a curve. However, equation (2) implies that we can go back to the standard case when the analysis is conducted conditioning on a particular asset, once the hedge term component is subtracted from the observed portfolio. That is, a Sharpe ratio can be used to test for efficiency in the mean variance space corresponding to the "unconstrained" assets, after allowance has been made for the presence of the same hedge term in all efficient portfolios.

\section{Application.}

To show the implications of our theoretical analysis we use data on Italian asset returns and household portfolios. Italy provides a good test case to study the effect of housing on portfolios because home ownership is wide spread and household stock market participation is relatively low

\footnotetext{
${ }^{1}$ For the sake of simplicity we do not stress in our notation that the test statistic is defined as a function of sample estimates of the first two moments of the rates of return distribution and takes observed portfolio shares as given.
} 
but has much increased in recent years. As we shall see, in Italy housing returns unambiguously correlate with financial returns, thus providing the need for a hedge term in house owners portfolios. Also, an attractive feature of Italy for our purposes is that pension wealth, whose amount is typically not recorded in survey data, is still almost entirely provided by the public pay-as-you-go social security system and is therefore both out of individual investors' control and not directly related to the financial markets performance. Finally, mortgages are rare compared to countries like the US or the UK, and particularly reverse mortgages (equity lines) are not yet available.

Italian households traditionally have held poorly diversified financial portfolios (Guiso and Jappelli, 2002). In the 1980s and even more in the 1990s, though, the stock exchange has grown considerably and mutual funds have become a commonly held financial instrument. Household financial accounts reveal that the aggregate financial portfolio share in stocks and funds amounted to $16.15 \%$ in $1985,20.69 \%$ in 1995 and rose to an unprecedented $46.95 \%$ in 1998 . It then fell sharply to $35.31 \%$ in 2002 . This growth in the equity market paralleled the sharp decrease in importance of bank accounts and short-term government debt in household portfolios. These aggregate statistics are uninformative on the participation issue, though. To this end, an analysis of survey data is required. The most widely used Italian survey data, the Bank of Italy-run Survey on Household Income and Wealth (SHIW), shows direct or indirect participation in equity markets (broadly defined to include life insurance and private pensions) to have increased from $26.43 \%$ in 1989 to $33.18 \%$ in 1995 and to $37.25 \%$ in 1998 ; this was followed by a relatively small decrease to $34.89 \%$ in 2002 . For comparison, the percentage of house-owners in the same sample hovered around $63-69 \%$ over the period.

These summary statistics clearly show that household financial portfolios have changed a great deal over the years, and that a key role in total household wealth is played by real estate. It makes sense to consider the interaction of housing and financial wealth holdings when assessing the efficiency of household portfolios, as stressed by Flavin and Yamashita (2002). A financial portfolio may deviate 
from the mean variance frontier for financial assets simply as a result of its covariance properties with the return on housing equity.

In our application we use household portfolio data for 2002 and asset return data for the period 1989-2002.

The 2002 SHIW wave contains detailed information on asset holdings of 8011 households as of 31.12.2002, as well as self assessed value of their housing stock (both principal residence and other real estate) and actual or imputed rent for each dwelling. For each household we also know the region of residence and a number of demographic characteristics. The survey does not over sample the very rich, and it therefore captures about a third of total household financial wealth. It does cover a relatively large number of assets, including individual pension funds: these are still remarkably unimportant in Italy, though, partly because of inadequate tax incentives. Occupation pension schemes are also relatively minor, even though recent reforms of the Italian Social Security system (particularly the Dini reform of 1995) imply that they should become wide-spread. ${ }^{2}$

Asset return data cover four major assets: short term government bonds (6 month BOT), corporate bonds, government bonds, and equity (the MSCI Italy stock index). We treat the short-term bond as risk free, and assume that this is the relevant return on bank deposits, once account is taken of nonpecuniary benefits. For bonds we derive the holding period returns (HPR) as follows. For government bonds we take the MSCI Italian Government bond index after 1993. Prior to December 1993 this index is not available, and we use our own estimates of the term structure based on quoted prices of Italian government bonds to determine the holding period return by assuming a duration of five years ${ }^{3}$. For corporate bonds we compute the HPR by deriving the prices consistent with the RENDIOBB index (the index of Italian corporate bonds yields) and assuming a duration of three years. We express all returns net of withholding tax, on the assumption that for most investors other tax distortions are relatively minor (financial asset income is currently subject to a $12.5 \%$

\footnotetext{
${ }^{2}$ Further information on the survey is provided in Guiso and Jappelli (2002) and Biancotti et al. (2004). Information on the Italian pension system and its recent reforms is presented in Brugiavini and Fornero (2001).

${ }^{3}$ We checked the quality of this procedure by regressing our monthly holding period returns on those of the MSCI Italian bond index over the period December 1993 to December 2002 and found an almost perfect fit.
} 
withholding tax. Housing is taxed on the basis of its ratable value, while actual rental income is taxed at the marginal income tax rate).

To evaluate the efficiency of households' portfolio we need to determine the expected return and the expected variance covariance matrix of the assets. Given long, stationary series we could simply compute the corresponding sample moments of the assets excess returns. However, this approach is unlikely to work in our case: our sample period is 1989-2002 (and cannot be extended because some assets did not exist prior to the mid 1980's), and in the 1990s we observe a long convergence process of Italian interest rates to German interest rates that accelerated dramatically in the few years before the introduction of the Euro on January 1999.

Estimation error is of particular concern for first moments and calls for use of prior information in estimation (see for instance Merton, 1980, and Jorion, 1985). In our case, we should estimate the first moments by a Bayesian method that exploits prior information on convergence of particularly long-term government bond rates to its German equivalent, and possibly a multivariate GARCH for the second moments. Unfortunately, we do not have enough data points to perform sophisticated estimation exercises. In fact, housing returns are available at a biannual frequency, and we are therefore forced to use at most twenty-nine data points. However, we can exploit prior information on convergence by using a simple Weighted Least Squares procedure, where the raw return series data are down weighted more the farther away they are from December 1998 (they have a unitary weight from 1999 on). More precisely, we construct the weights to be a geometrically declining function of the lag operator multiplied by $\alpha$ (where $\alpha$ is set to 0.9 ). The weighted series are used to compute sample first and second moments ${ }^{4}$.

In Table 1 we show the first and second moments of the excess returns data we use (1989-2002). These are expressed as percentage annual rates of return net of the time-varying risk-free rate.

\footnotetext{
${ }^{4}$ A similar procedure for second-order moments is often used in the financial industry (see RiskMetrics, 1999) and can be shown to be equivalent to particular GARCH models (Phelan, 1995).
} 
Table 1: Sample first and second moments of annual excess returns

\begin{tabular}{|c|r|r|r|}
\hline & $\begin{array}{c}\text { Government } \\
\text { Bonds }\end{array}$ & $\begin{array}{c}\text { Corporate } \\
\text { Bonds }\end{array}$ & \multicolumn{1}{|c|}{ Stocks } \\
\hline Expected return \% & 4.0981 & 2.2845 & 4.9011 \\
\hline Standard Deviation \% & 5.2383 & 3.2169 & 28.9950 \\
\hline
\end{tabular}

\begin{tabular}{|c|c|c|r|}
\hline CORRELATION & $\begin{array}{c}\text { Government } \\
\text { Bonds }\end{array}$ & $\begin{array}{c}\text { Corporate } \\
\text { Bonds }\end{array}$ & \multicolumn{1}{|c|}{ Stocks } \\
\hline Government Bonds & 1 & 0.8404 & $\mathbf{0 . 0 2 1 5}$ \\
\hline Corporate Bonds & & 1 & $\mathbf{0 . 1 7 2 6}$ \\
\hline Stocks & & & 1 \\
\hline
\end{tabular}

We see that stocks have higher expected excess return $(4.9 \%)$ and higher variance than all other risky financial assets. Government bonds also have high expected excess return (4.1\%), due to their long maturity. Corporate bonds rank last both in terms of expected excess return (2.3\%) and variance.

It is comforting to see that our estimated excess return on equity $(4.9 \%)$ is not far from what is normally found using much longer sample periods: Dimson et al. (2006) report a 5.7\% average equity premium over the 1950-2000 period, in line with secular evidence provided by Panetta and Violi (1999). Our expected excess return for corporate bonds is also similar to the one reported by Dimson et al (2006) for medium term bonds (2.5\%) over the 1950-2000 period. Long term government bonds unfortunately did not exist prior to our estimation period, so no comparison with other sources is possible.

Correlation coefficients between bonds are quite high (.84) - correlation coefficients of stocks and bonds are positive, but much smaller. Not surprisingly, stock returns correlate more with corporate bonds (.17) than with government bonds (.02).

This picture is however largely incomplete. We know that two households out of three own real estate, and we argued that this type of investment is highly illiquid. Even those who do not own housing stock consume housing services and should hedge the risk of future purchases of either stocks or services. It is therefore of great interest for us to compute first and second moments of the housing stock. To this end we use province-level biannual price data (source: Consulente 
Immobiliare) covering the whole 1989-2002 period. We compute the return on housing according to the formula:

(7) $\quad r_{H, t}=\frac{P_{t}-P_{t-1}}{P_{t-1}}+\frac{D_{t}-C O M_{t}}{P_{t-1}}=\frac{P_{t}-P_{t-1}}{P_{t-1}}+\kappa$

where $D$ denotes rent and $C O M$ maintenance costs. Given that we lack time series information on these, we set $\kappa=.025$ (5\% on an annual basis), as in Flavin and Yamashita (2002). It is worth stressing that the choice of $\kappa$ is immaterial in our analysis, as long as $\kappa$ is a fixed number (see equation 2 , where $\mu_{\mathrm{H}}$ does not appear). We in fact take housing positions as given, and the expected excess return on housing plays no role in evaluating whether financial portfolios are conditionally efficient.

Finally, we aggregate housing returns to the macro-region level (we use provincial resident population numbers to generate weights). The first and second moments are then determined using (prior to 1999) the time-varying weights described above.

Our regional classification splits the country in North West (that includes the three large industrial cities of Milan, Turin and Genoa), the North East (that includes many middle-sized cities and towns, such as Bologna, Venice, Verona, Trieste), the Centre (that includes the capital city, Rome, and many medium-sized town such as Florence, Perugia and Ancona) and the South (largely rural, but including Naples and Bari). The two large islands, Sicily and Sardinia, are also counted as South here.

Table 2 reveals that expected excess returns on housing are highest in the North East and in the South and lowest in Central Italy (they range between 3.3\% and 4.2\% on an annual basis). They are close to returns on bonds, but are much lower than returns on stocks. Housing excess return standard deviations range between $5.1 \%$ and $6.5 \%$, and are therefore much lower than on stocks, but comparable to bonds. Of interest to us is the negative correlation between housing returns and most financial asset returns. 
Table 2: Expected excess returns and correlation matrix of housing (1989-2002)

\begin{tabular}{|c|l|l|r|r|}
\hline & \multicolumn{1}{|c|}{ NW } & \multicolumn{1}{c|}{ NE } & \multicolumn{1}{c|}{ Centre } & \multicolumn{1}{c|}{ South } \\
\hline Expected excess return \% & 3.2922 & 4.1883 & 3.2791 & 3.3036 \\
\hline Standard deviation \% & 5.5774 & 5.0755 & 6.5381 & 5.0715 \\
\hline
\end{tabular}

\begin{tabular}{|c|c|c|c|c|}
\hline & NW & NE & Centre & \multicolumn{1}{l|}{ South } \\
\hline Government bonds & -0.0164 & -0.1169 & -0.1161 & -0.2036 \\
\hline Corporate bonds & -0.0843 & -0.1691 & -0.2177 & -0.1998 \\
\hline Stocks & -0.5057 & -0.2790 & -0.4172 & -0.1506 \\
\hline
\end{tabular}

The issue arises of whether these correlations are negligible. The simplest way to assess this is to estimate the coefficients of the hedge term in equation (2), that is to estimate the beta hedge ratio $\Sigma^{-1} \Gamma_{b P}$. This can be done by running the regression of housing returns on financial asset returns, as suggested by de Roon, Eichholtz and Koedijk (2002). Parameter estimates and their standard errors are summarized in Table 3.

Table 3: Regression of excess return on housing on financial assets excess returns

\begin{tabular}{|ccccc|}
\hline Variable & North West & North East & Centre & South \\
\hline \multirow{2}{*}{ Constant } & 2.6378 & 2.8218 & 2.7910 & 2.8088 \\
& $(0.556)$ & $(0.591)$ & $(0.737)$ & $(0.565)$ \\
$\mathbf{r}_{\text {GOv. }}$ & -0.0128 & 0.0392 & 0.1190 & -0.1461 \\
& $(0.280)$ & $(0.297)$ & $(0.371)$ & $(0.284)$ \\
$\mathbf{r}_{\text {CORP }}$ & -0.2757 & -0.5013 & -0.7619 & -0.3794 \\
& $(0.477)$ & $(0.507)$ & $(0.632)$ & $(0.484)$ \\
$\mathbf{r}_{\text {STOCKS }}$ & -0.0968 & -0.0427 & -0.0844 & -0.0232 \\
& $(0.028)$ & $(0.030)$ & $(0.0374)$ & $(0.0287)$ \\
& & & & 0.012 \\
\hline \multirow{2}{*}{ p-value } & 0.001 & 0.030 & 0.015 & .405 \\
\hline \multirow{2}{*}{$\mathbf{R}^{2}$} & .523 & .350 & .390 & \\
\hline Notes: Standard errors in parentheses. & Number of observations $=28$
\end{tabular}

We see that in two regions ( $\mathrm{NW}$ and $\mathrm{CE}$ ) there is at least one non-zero parameter at the $95 \%$ significance level and in all regions the slope coefficients are jointly significantly different from zero at the $95 \%$ level (the p-value of the F-test is reported at the bottom of the table, together with the $\mathrm{R}^{2}$ ). The regions where this test is least significant are the North East (with a p-value of $3 \%$ ). 
On the basis of this evidence, we conclude that housing returns present significant correlations with financial asset returns in Italy, and this provides the basis for introducing a hedge term in household portfolios of house-owners. De Roon, Eichholtz and Koedijk (2002) find that a similar result is also true for some areas in the U.S., but do not analyze the efficiency of U.S. household portfolios. We also find evidence, available upon request, of significant correlations with excess returns on at least some financial assets in other European countries (France, Germany, Spain and the UK).

In Table 4 we report the percentage participation for each asset and liability recorded in SHIW2002. For instance, we see that over $74 \%$ of the sampled households have a bank current (i.e. checking) account, and almost $17 \%$ have the post-office equivalent.

We also show in the last column of Table 4 where each asset is classified, given that we use asset returns data at a much coarser aggregation level. So, for instance, five of the first seven assets (cash, various deposits) are classified as risk-free.

Of particular interest is the relatively low direct stock market participation $(9 \%$ hold listed shares; less than $1 \%$ shares in unlisted companies). However, $10.76 \%$ of all households have mutual funds: in particular, $4.17 \%$ have stock funds, $3.16 \%$ bond funds, $5.12 \%$ mixed funds and $1.13 \%$ have monetary funds. These holdings we classify as stocks, government bonds, corporate bonds or riskfree asset on the basis of recorded information on the type of mutual fund held and industry wide information on average investments by type (Assogestioni). We similarly split holdings in managed savings into government bonds, corporate bonds and stocks. Of great relevance for our analysis is also the high proportion of households who own some housing stock (almost 70\%). Liabilities are relatively little wide-spread (10\% households report mortgage; $11 \%$ other forms of consumer debt). We split mortgages in three groups: fix-interest mortgages (3\%), floating-interest mortgages (4\%) and mortgages intended for home-improvement (3\%). We treat fix-interest mortgages as negative positions on government bonds (the longest maturity bonds available in Italy) and floating-interest mortgages as negative positions on the risk-free asset. 
Table 4: Participation decision - individual financial and real assets

\begin{tabular}{|l|r|r|}
\hline Asset & Participation & Broad Asset \\
\hline Cash & $100 \%$ & Risk-free \\
\hline Bank Current Account Deposits & $74.07 \%$ & Risk-free \\
\hline Bank Savings Deposits (Registered) & $11.00 \%$ & Risk-free \\
\hline Bank Savings Deposits (Bearer) & $2.01 \%$ & Risk-free \\
\hline Certificates of deposit & $118 \%$ & Gov. Bonds \\
\hline Repos & $0.50 \%$ & Gov. Bonds \\
\hline Post Office Current Accounts and & $16.86 \%$ & Risk-free \\
Deposit Books & & \\
\hline Post Office Savings Certificates & $4.76 \%$ & Gov. Bonds \\
\hline BOT (Italian T-bills) & $7.13 \%$ & Gov. Bonds \\
\hline CCT (Italian T-certificates) & $2.05 \%$ & Gov. Bonds \\
\hline BTP (Italian T-bonds) & $1.96 \%$ & Gov. Bonds \\
\hline CTZ (Italian zero-coupon) & $0.38 \%$ & Gov. Bonds \\
\hline Other Italian Government Debt (CTE, & $0.22 \%$ & Gov. Bonds \\
CTO, etc.) & & Corp. Bonds \\
\hline Corporate Bonds & $6.00 \%$ & Stocks \\
\hline Mutual Funds & $10.76 \%$ & Bonds \& Stocks \\
\hline Shares of listed companies & $9.05 \%$ & Stocks \\
\hline of which: of privatized companies & $4.80 \%$ & Stocks \\
\hline Shares of unlisted companies & $0.89 \%$ & Stocks \\
\hline Shares of limited liability companies & $0.18 \%$ & Bonds \\
\hline Managed Savings & $1.98 \%$ & Bonds \& Stocks \\
\hline Foreign bonds and government \\
securities
\end{tabular}

Notes: Number of observations: 8011. Population weights have been used.

We treat mortgages for home-improvement and other debt as negative positions on corporate bonds because these debt contracts are normally fix-interest and medium-term maturity. The analysis of Section 1 and the Appendix highlights that the relevant wealth concept is the sum of financial wealth, human capital, and housing wealth net of the present value of future rents (PVR) and total debt. Two key variables are not directly observable and have to be constructed: human capital and the present value of housing needs. 
In principle, for each individual in SHIW 2002 we would like to know current and future earnings, current and future pension income, as well as retirement and survival probabilities. This would produce the best possible estimate of human capital wealth. Similarly, for each household in the sample, we would like to know current rent (actual or imputed) and its likely changes in the future that relate to changes in family size and composition, to retirement or death of either spouse, or indeed to changes in economic circumstances of the household. These data, combined with survival probabilities, could be used to calculate a household-specific measure of the PVR, the present value of current and future housing needs.

Only a small part of these data are available in SHIW 2002, but further relevant information can be found in previous waves of SHIW (that refer to 1989, 1991, 1993, 1995, 1998 and 2000).

The method we adopt is to use the pooled SHIW data to estimate some relations (for earnings and rent), controlling for age, year of birth and a few characteristics, and use the estimated profiles to project forward the current values reported by SHIW 2002 respondents. These projections are then multiplied by the relevant (age and gender specific) survival probabilities and discounted to get a household-specific estimate of Human Capital and PVR.

Let us consider human capital first. We take individual real earnings for all working individuals in SHIW 1989-2002 (58835 observations in all, spread over 7 different sampling periods), and estimate a multiple regression equation as a function of a second order polynomial in age, education and gender dummies, plus twenty cohort dummies (based on three year intervals for the year of birth). Macroeconomic effects are assumed to be in the error term. The estimated age profile is shown in Figure 2. This is used to impute future earnings to SHIW 2002 observations as follows: an individual reports her current earnings, expected retirement age and replacement rate.

Future earnings up to the expected retirement age are obtained by assuming their growth to be as estimated in the SHIW sample. After retirement, the expected replacement rate determines the first pension payment. Further payments are assumed to be constant in real terms (in agreement with current legislation for public pensions). In the case of couples, we take into account that survivor 
pensions are $60 \%$ of the original pension. Age, gender and cohort-specific survival probabilities are used to computed expected earnings and pensions; all future terms are discounted at the risk-free rate (net of inflation).

Figure 2: Estimated age profile for earnings

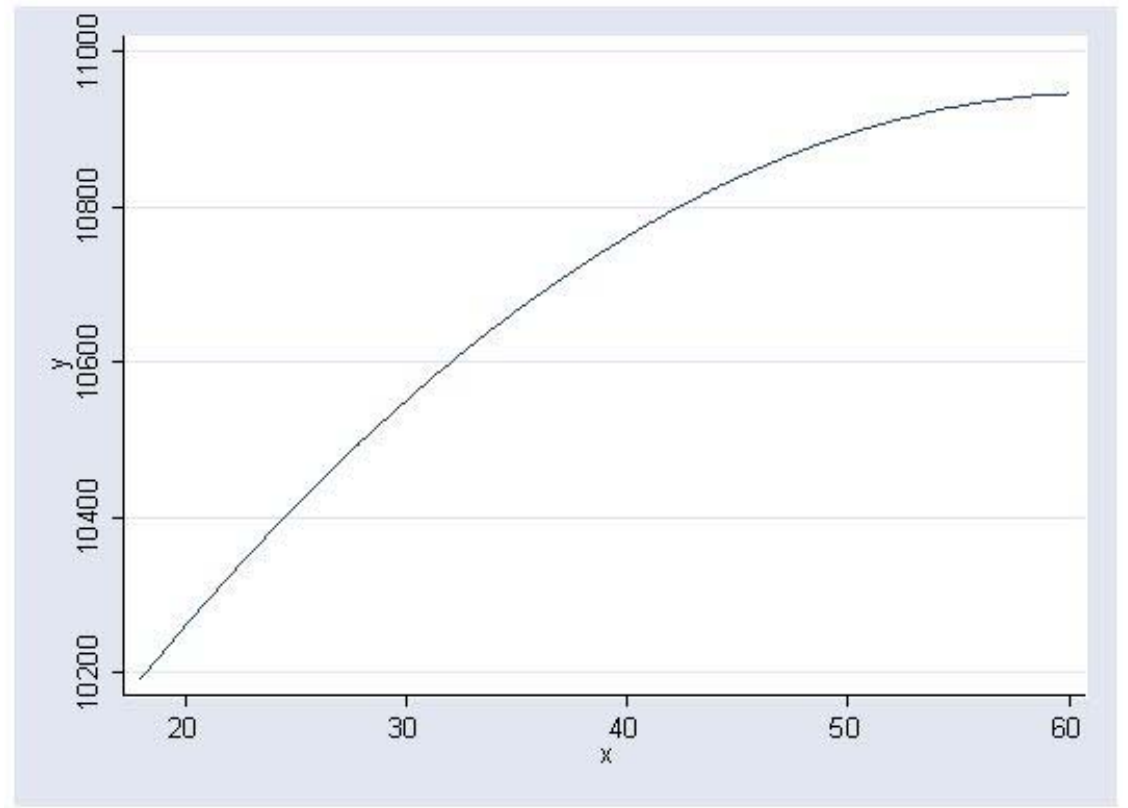

The Present Value of Rent was computed along similar lines, using data on actual or imputed rent for the main residence. A real rent equation was estimated at the household level on pooled SHIW data, conditioning on a second-order polynomial in head's age, a tenant dummy plus a set of cohort dummies as described above. The estimation sample has 53367 observations in all.

Figure 3 shows the estimated age profile. The most remarkable feature of this profile is that there is a hump. The initial rise with age is likely due to trading up and/or major home improvements typical of household formation and birth of children. The fall with age estimated to occur after age 58 may be related to actual trading down (purchase of smaller homes once the children have left) or, more likely in the Italian context, to a failure to carry out maintenance and repairs.

The PVR was calculated for each SHIW 2002 household starting from their reported rent, letting future rents evolve according to the estimated profile plus the expected return on housing, taking into account each spouse's survival probability, and discounting at the expected return on housing 
in agreement with our theoretical model. We should stress that most of the age variability in PVR is induced by finite lives, not by the hump-shaped profile shown in Figure 3.

Our empirical strategy allows for heterogeneity in preferences and/or opportunity sets by taking the current home as an individual-specific basis for the calculation of future needs. We then use (for lack of better, individual-level information) average growth rates in housing consumption (assumed proportional to the real home value) to project forward future needs, and allow for survival probabilities to compute the present value of future housing consumption.

\section{Figure 3: Estimated age profile for rent}

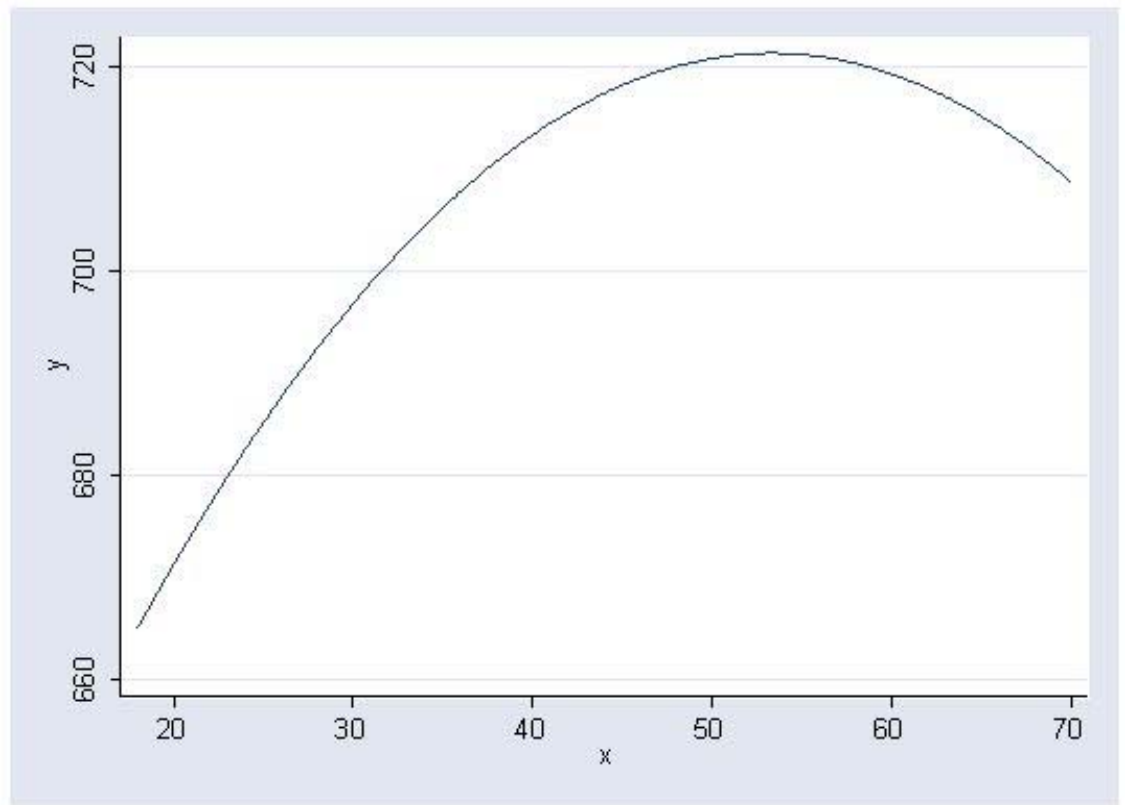

In the rest of the paper, we focus on those observations with valid records of financial assets and housing stock values and for which we have been able to derive an estimate of both human capital and the present value of rent. This occurs in 7457 cases out of 8011.

Table 5 shows average and median amounts for the broad assets and liabilities we consider: four financial assets, three types of debt, housing, the present value of rent and human capital. We see that financial assets are a relatively small component of total wealth: their average is in the $€ 23,000$ region, whilst average total wealth is close to $€ 500,000$. By far the largest component of total wealth is human capital, which is computed as the present value of future earnings and pension payments and is treated as a risk-free asset. This is a constructed variable, and therefore sensitive to 
the particular assumptions made on discount factors, earnings and pensions age profiles, survival probabilities and so forth. For this reason, we have carried out robustness checks of our efficiency analysis with respect to the value of the risk-free position.

Table 5: Amounts held in financial and real assets

\begin{tabular}{|l|c|c|c|}
\hline Asset & $\begin{array}{c}(\mathbf{1}) \\
\text { Average }\end{array}$ & $\begin{array}{c}\mathbf{( 2 )} \\
\text { Median }\end{array}$ & $\begin{array}{c}\mathbf{( 3 )} \\
\text { Conditional Average }\end{array}$ \\
\hline Risk-free Financial Assets & 12,728 & 5,200 & 15,410 \\
\hline Government Bonds & 4,885 & 0 & 14,136 \\
\hline Corporate Bonds & 2,638 & 0 & 7,632 \\
\hline Stocks & 3,232 & 0 & 9,531 \\
\hline Total Financial Assets & $\mathbf{2 3 , 4 8 2}$ & $\mathbf{7 , 2 5 0}$ & $\mathbf{4 6 , 7 0 9}$ \\
\hline Fix-rate mortgages & 1,048 & 0 & 3,033 \\
\hline Floating-rate mortgages & 1,299 & & 1,334 \\
\hline Other debt and mortgages & 949 & 0 & 2,745 \\
\hline Housing & 132,853 & 100,000 & 204,110 \\
\hline Present Value of Rents & 141,988 & 99,985 & 186,417 \\
\hline Human Capital & 485,872 & 366,224 & 651,173 \\
\hline Total Wealth & $\mathbf{4 9 6 , 9 2 4}$ & $\mathbf{3 6 8 , 2 4 2}$ & $\mathbf{7 0 8 , 2 8 2}$ \\
\hline
\end{tabular}

Note: number of observations in columns (1) and (2) =7457; in column (3): 2577

The second largest components of household wealth are the housing stock and the present value of rents. Their average value is of similar magnitude, but for individual households these two differ considerably over the life-cycle. Younger households are typically under-housed, in the sense that their future needs are worth more than their current housing stock. Older households instead tend to be over-housed (with the notable exception of renters), because the present value of their future rents is reduced by the shortening time horizon, other things being equal.

Even within financial assets, Table 5 reveals that the risk-free position accounts for the largest fraction; with an average of almost $€ 13,000$ (the same is true if we look at the medians). The three risky assets account for an average of $€ 10,000$ overall (their median holdings are instead zero, because participation is not sufficiently wide-spread). Debt positions are relatively small; even though mortgages are sometimes quite large (they exceed $€ 77,000$ for $1 \%$ of the sample).

Column (3) of Table 5 presents average holdings for those households who have some financial risky assets or liabilities. The number of observations falls to just 2577 - this is the relevant sample for most of our analysis. This sample is overall richer: average financial wealth is almost twice as 
high as in the full sample, with much larger values for risky financial assets (accounting for $€$ 31,000 overall). Total wealth is also higher, but by a more modest $42 \%$.

It is worth recalling that in our efficiency analysis, we treat fix-rate mortgages as negative holdings of government bonds (the only long term bonds available are on government debt), floating-rate mortgages as negative positions on the risk-free asset and all other debt (including homeimprovement mortgages) as negative holdings of corporate bonds (other debt typically has medium term maturity like corporate bonds). Thus a household with risk-free assets and a fix-rate mortgage or other debt belongs to this "well diversified" group.

The distinction between households with at least some risky financial assets or liabilities and the remaining households is of particular relevance for us, because for the latter group the test statistic takes the same value for all households in the same broad region. In Table 6 we show how this classification changes according to the broad regions introduced earlier (see Tables 2 and 3 ).

Table 6 - Classification by Region.

\begin{tabular}{|c|c|c|c|c|c|c|c|c|c|c|}
\hline & \multicolumn{2}{|c|}{ Total } & \multicolumn{2}{|c|}{ NW } & \multicolumn{2}{|c|}{ NE } & \multicolumn{2}{|c|}{ Centre } & \multicolumn{2}{|c|}{ South } \\
\hline & $n^{\circ}$ & $\%$ & $\mathbf{N}^{\circ}$ & $\%$ & $\mathbf{N}^{\circ}$ & $\%$ & $n^{\circ}$ & $\%$ & $\mathbf{N}^{\circ}$ & $\%$ \\
\hline $\begin{array}{l}\text { Risk-free asset }+ \\
\text { housing }\end{array}$ & 4880 & 65.44 & 1120 & 56.22 & 802 & 53.18 & 922 & 60.22 & 2036 & 83.92 \\
\hline $\begin{array}{l}\text { Risk-free + risky } \\
\text { assets/ liabilities } \\
+ \text { housing }\end{array}$ & 2577 & 34.56 & 872 & 43.78 & 706 & 46.82 & 609 & 39.78 & 390 & 16.08 \\
\hline Total assets & 7457 & & 1992 & & 1508 & & 1531 & & 2426 & \\
\hline
\end{tabular}

We see that the highest proportion of risk-free financial asset portfolios $(83.92 \%)$ is found in the South, the lowest in the North East (53.18\%). This implies that the sample size for our efficiency test differs a lot from the total sample in its regional composition, with a much smaller fraction of households resident in the Southern regions $(15.13 \%$ as opposed to $32.53 \%)$. However, the relative proportions of households resident in the three other macro regions is roughly in line with the full sample. 


\section{Optimal portfolio allocation and efficiency test results}

The return data we have described in the previous section have clear-cut implications for optimal portfolio weights, according to equation (2). Also, they can be used to assess the efficiency of actual household portfolios, using the test statistic shown in equation (5).

\subsection{Optimal Portfolio allocations}

The normative predictions of our model are best understood if we split the sample in three age groups and take average values of total wealth, human capital, gross housing wealth and net present value of rents (PVR) for each. For the sake of brevity we consider here only households who live in the NW region, as these typically have more diversified financial portfolios (we concentrate on those that hold at least one risky asset).

We define the oldest group to include homeowners whose head is 70 or more years of age $(\mathrm{N}=$ 137 ); they are typically over-housed (their gross housing wealth is $€ 262,102$ whilst their PVR is $€$ 66,695), and have relatively low human capital ( $€$ 237.166). The middle group consists of homeowners whose head is 50-69 years old $(\mathrm{N}=357)$ - they have positive net housing wealth (their gross housing wealth is $€ 252,416$ whilst their PVR is $€ 157,427$ ), and have relatively high human capital $(€ 590,013)$. The youngest group includes homeowners whose head is less than $50(\mathrm{~N}=229)$ : their net housing is substantially negative, their human capital very large. We do not display results for renters $(\mathrm{N}=148)$, because they are quite similar to this last group, even though their human capital wealth is less large.

Throughout Table 7 we consider the case where the relative risk aversion parameter is unity.

In column 1 of Table 7 we show optimal portfolios for our model, that adopts a "net housing" concept and uses the estimated correlations between housing and financial assets returns. The optimal portfolios weights for bonds are relatively constant across age groups (around 12\%) - major differences occur instead for corporate bonds and stocks. For the older group, that is over-housed, corporate bonds should be $18.55 \%$ and stocks $4.14 \%$ of total wealth. In absolute terms, these 
households should on average invest little over $€ 20,000$ in stocks. For the youngest group, instead, the optimal portfolio weight in corporate bonds is just $3.16 \%$, whilst the weight for stocks is negative $(-0.66 \%)$. These households should short stocks by $€ 6,384$ on average.

Column 2 presents optimal portfolios for the case where the correlation coefficients between housing and financial assets returns are all zero. This corresponds to equation (1) and generates Markowitz portfolio weights. For comparability with column 1, we keep using our net housing definition (column 4 presents the alternative case where the liability aspect is neglected - this is exactly the case considered by Flavin and Yamashita, 2002. Portfolio weights are the same in columns 2 and 4, but values are different because total wealth is different). In this case, portfolio weights are constant across age groups. The weight on corporate bonds is $6.63 \%$, much smaller than in column 1 for all but the youngest group. The optimal weight on stocks is positive but very close to zero (implying positive positions between $€ 2,000$ and $€ 4,000$ - comparable to the average holdings reported in table 5).

Column 3 presents optimal portfolio weights for the case where housing is just an asset (as in this model when rent is uncorrelated with house prices - see also Pelizzon and Weber, 2007). Households should invest more in corporate bonds and stocks compared to the case shown in column 1, and they should never take short positions in stocks. As in column 1 there is an age pattern in stocks, with the oldest investing more than the youngest, but the difference is relatively minor. This highlights the crucial role played by the PVR in generating sharply different prescriptions by age. 
Table 7 - Optimal portfolios by age for a unit relative risk aversion coefficient.

\begin{tabular}{|c|c|c|c|c|}
\hline & $(1)$ & $(2)$ & (3) & $(4)$ \\
\hline \multicolumn{5}{|c|}{ Old-aged $70+$} \\
\hline & $\begin{array}{c}\text { Estimated } \\
\text { Correlations } \\
\text { Net Housing }\end{array}$ & $\begin{array}{c}\text { Zero } \\
\text { Correlations } \\
\text { Net Housing }\end{array}$ & $\begin{array}{c}\text { Estimated } \\
\text { Correlations } \\
\text { Gross Housing }\end{array}$ & $\begin{array}{c}\text { Zero } \\
\text { Correlations } \\
\text { Gross Housing }\end{array}$ \\
\hline \multicolumn{5}{|c|}{ Descriptive statistics: sample averages } \\
\hline Total Wealth & 504,275 & 504,275 & 570,971 & 570,971 \\
\hline Human Capital & 237,166 & 237,166 & 237,166 & 237,166 \\
\hline Housing & 262,102 & 262,102 & 262,102 & 262,102 \\
\hline PVR & $-66,695$ & $-66,695$ & 0 & 0 \\
\hline \multicolumn{5}{|c|}{ Optimal Portfolio Weights } \\
\hline Bonds \% & $11.67 \%$ & $12.06 \%$ & $11.60 \%$ & $12.06 \%$ \\
\hline CB \% & $18.55 \%$ & $6.63 \%$ & $20.76 \%$ & $6.63 \%$ \\
\hline Stocks \% & $4.14 \%$ & $0.42 \%$ & $4.83 \%$ & $0.42 \%$ \\
\hline \multicolumn{5}{|c|}{ Optimal Portfolio Holdings for Average Wealth } \\
\hline Bonds & 58,851 & 60,793 & 66,229 & 68,833 \\
\hline Corporate Bonds & 93,560 & 33,425 & 118,507 & 37,845 \\
\hline Stocks & 20,881 & 2,130 & 27,563 & 2,411 \\
\hline \multicolumn{5}{|c|}{ Young old - 50-69 of age } \\
\hline & $\begin{array}{c}\text { Estimated } \\
\text { Correlation } \\
\text { Net Housing }\end{array}$ & $\begin{array}{c}\text { Zero } \\
\text { Correlations } \\
\text { Net Housing }\end{array}$ & $\begin{array}{c}\text { Estimated } \\
\text { Correlations } \\
\text { Gross Housing }\end{array}$ & $\begin{array}{c}\text { Zero } \\
\text { Correlations } \\
\text { Gross Housing }\end{array}$ \\
\hline \multicolumn{5}{|c|}{ Descriptive statistics: sample averages } \\
\hline Total Wealth & 752,904 & 752,904 & 910,331 & 910,331 \\
\hline Human Capital & 590,013 & 590,013 & 590,013 & 590,013 \\
\hline Housing & 252,416 & 252,416 & 252,416 & 252,416 \\
\hline PVR & $-157,427$ & $-157,427$ & 0 & 0 \\
\hline \multicolumn{5}{|c|}{ Optimal Portfolio Weights } \\
\hline Bonds \% & $11.93 \%$ & $12.06 \%$ & $11.78 \%$ & $12.06 \%$ \\
\hline СВ \% & $10.51 \%$ & $6.63 \%$ & $15.16 \%$ & $6.63 \%$ \\
\hline Stocks \% & $1.63 \%$ & $0.42 \%$ & $3.08 \%$ & $0.42 \%$ \\
\hline \multicolumn{5}{|c|}{ Optimal Portfolio Holdings for Average Wealth } \\
\hline Bonds & 89,822 & 90,766 & 107,236 & 109,744 \\
\hline Corporate Bonds & 79,137 & 49,904 & 138,020 & 60,339 \\
\hline Stocks & 12,295 & 3,179 & 28,067 & 3,844 \\
\hline
\end{tabular}

Note: This table shows descriptive statistics and optimal portfolio weights and holdings for different concepts of housing wealth (net of present value of rents, or gross) and for different estimates of the partial correlation coefficients between housing and financial returns (as estimated and reported in Table 3, or zeros). All computations refer to the sample of homeowners who have at least one risky financial asset in their portfolios, and who live in the North-West region. 
Table 7 (cont.) - Optimal portfolios by age for a unit relative risk aversion coefficient.

\begin{tabular}{|c|c|c|c|c|}
\hline & (1) & (2) & (3) & (4) \\
\hline \multicolumn{5}{|c|}{ Young - less than 50 years of age } \\
\hline & $\begin{array}{c}\text { Estimated } \\
\text { Correlation } \\
\text { Net Housing }\end{array}$ & $\begin{array}{c}\text { Zero } \\
\text { Correlations } \\
\text { Net Housing }\end{array}$ & $\begin{array}{c}\text { Estimated } \\
\text { Correlations } \\
\text { Gross Housing }\end{array}$ & $\begin{array}{c}\text { Zero } \\
\text { Correlations } \\
\text { Gross Housing }\end{array}$ \\
\hline \multicolumn{5}{|c|}{ Descriptive statistics: sample averages } \\
\hline Total Wealth & 968,367 & 968,367 & $1,286,754$ & $1,286,754$ \\
\hline Human Capital & $1,037,479$ & $1,037,479$ & $1,037,479$ & $1,037,479$ \\
\hline Housing & 209,247 & 209,247 & 209,247 & 209,247 \\
\hline PVR & $-318,387$ & $-318,387$ & 0 & 0 \\
\hline \multicolumn{5}{|c|}{ Optimal Portfolio Weights } \\
\hline Bonds \% & $12.17 \%$ & $12.06 \%$ & $11.89 \%$ & $12.06 \%$ \\
\hline СВ \% & $3.16 \%$ & $6.63 \%$ & $11.63 \%$ & $6.63 \%$ \\
\hline Stocks \% & $-0.66 \%$ & $0.42 \%$ & $1.98 \%$ & $0.42 \%$ \\
\hline \multicolumn{5}{|c|}{ Optimal Portfolio Holdings for Average Wealth } \\
\hline Bonds & 117,825 & 116,741 & 153,045 & 155,124 \\
\hline Corporate Bonds & 30,598 & 64,186 & 149,685 & 85,290 \\
\hline Stocks & $-6,384$ & 4,089 & 25,514 & 5,434 \\
\hline
\end{tabular}

In Table 8 we present the Markowitz portfolios weights for higher values of relative risk aversion: all weights decline and the stock weight is as small as $0.14 \%$ when the coefficient of relative risk aversion is 3 . We do not show the effects for columns (1) and (3), as they are easily worked out.

Table 8 - Optimal Markowitz portfolios and risk aversion

\begin{tabular}{|lcccc|}
\hline \multicolumn{5}{c|}{$\begin{array}{c}\text { Portfolio weights } \\
\text { RRA }\end{array}$} \\
\hline & $\mathbf{1}$ & $\mathbf{2}$ & $\mathbf{3}$ & $\mathbf{4}$ \\
\hline Bonds & $12.06 \%$ & $6.03 \%$ & $4.02 \%$ & $3.01 \%$ \\
CB & $6.63 \%$ & $3.31 \%$ & $2.21 \%$ & $1.66 \%$ \\
Stocks & $0.42 \%$ & $0.21 \%$ & $0.14 \%$ & $0.11 \%$ \\
\hline
\end{tabular}

The results shown in Table 7 and 8 highlight the crucial role played by the liability aspect of housing in generating age effects on optimal portfolios: even in a model with no mean reversion in stock returns, or estimation risk, we obtain that portfolio weights of stocks should depend on age. In particular, we find that stock holding should increase with age. 
We conjecture that this last prediction would be weakened if there was mean reversion in stock returns (see Campbell and Viceira, 2002, for an appraisal); it would be strengthened if estimation risk was taken into account (given that estimation risk is highest for the young - Barberis, 2000).

\subsection{Efficiency Test Results}

We compute the efficiency test statistic described in Section 1 (see equation 5) for all the 7457 household portfolios observed in our data. However, a distinction must be made between the 4880 households who report not having any risky financial assets or liabilities, and the 2577 who instead have at least one such asset or liability. For the former group, by construction the test statistic takes the same value for all households within the same macro-region, irrespective of the amount held in either asset. For the latter group, instead, the test statistic varies across observations, depending on their risky asset shares.

For instance, for all 1049 households who live in the NW and have no risky assets, the test statistic takes a value of 6.34. Under the null of efficiency, this is distributed as a chi-squared random variable with 2 degrees of freedom. The corresponding critical values are 4.60 (test size: 10\%), 5.99 (test size: 5\%) and 9.21 (test size: 1\%). Thus the test always rejects when we choose a $90 \%$ significance level, it also rejects at the $95 \%$ level but not at the $99 \%$ level. For the NE, the calculated statistics is 2.39 , for Centre it is $4.30,0.41$ for households who live in the South, and therefore all these portfolios are efficient for any sensible test size.

It is worth stressing that the test statistic is based on the squared of the Sharpe ratio, thus portfolios with Sharpe ratios of the same magnitude but opposite sign are treated in the same way. In our discussion so far we have ignored this feature.

To better understand this point, and the working of conditional efficiency analysis in general, we can use the apparently conventional mean - standard deviation representation, along the lines already shown in Figure 1. In Figures 5 and 6, we represent all portfolios of residents in two macro- 
regions (NW and SO) who do not own any financial risky assets. We use the December 2002 six month Italian Treasury bill interest rate $(2.5 \%)$ as the risk-free rate.

The portfolios are represented net of the hedge term corresponding to Table 3 estimates and the specific net housing position (see equation 2). Hence in this simple case positive housing portfolios, net of the hedge term, are short on stocks (and bonds); negative housing portfolios are long on stocks (and bonds).

Figure 5. Efficiency analysis for portfolios with no risky financial assets in the North-West.

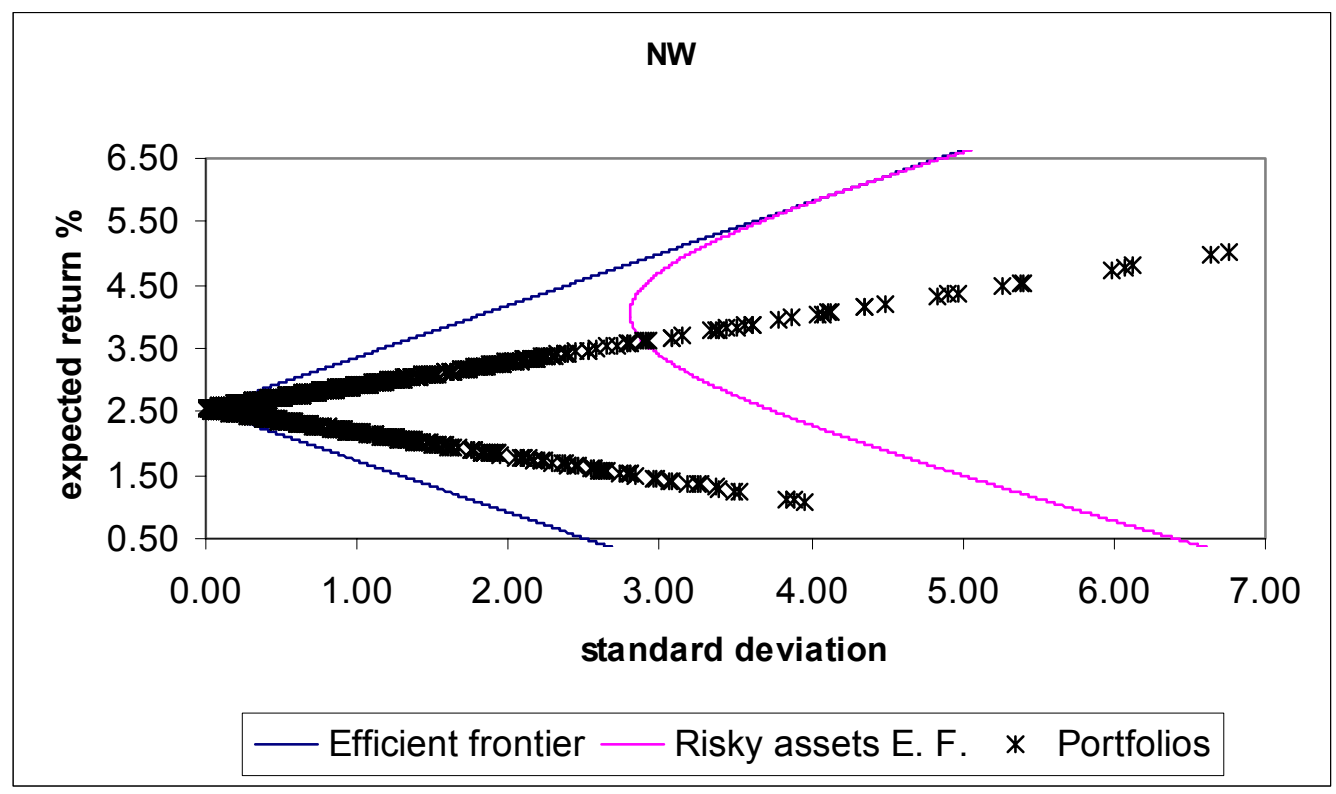

Figure 6. Efficiency analysis for portfolios with no risky financial assets in the South.

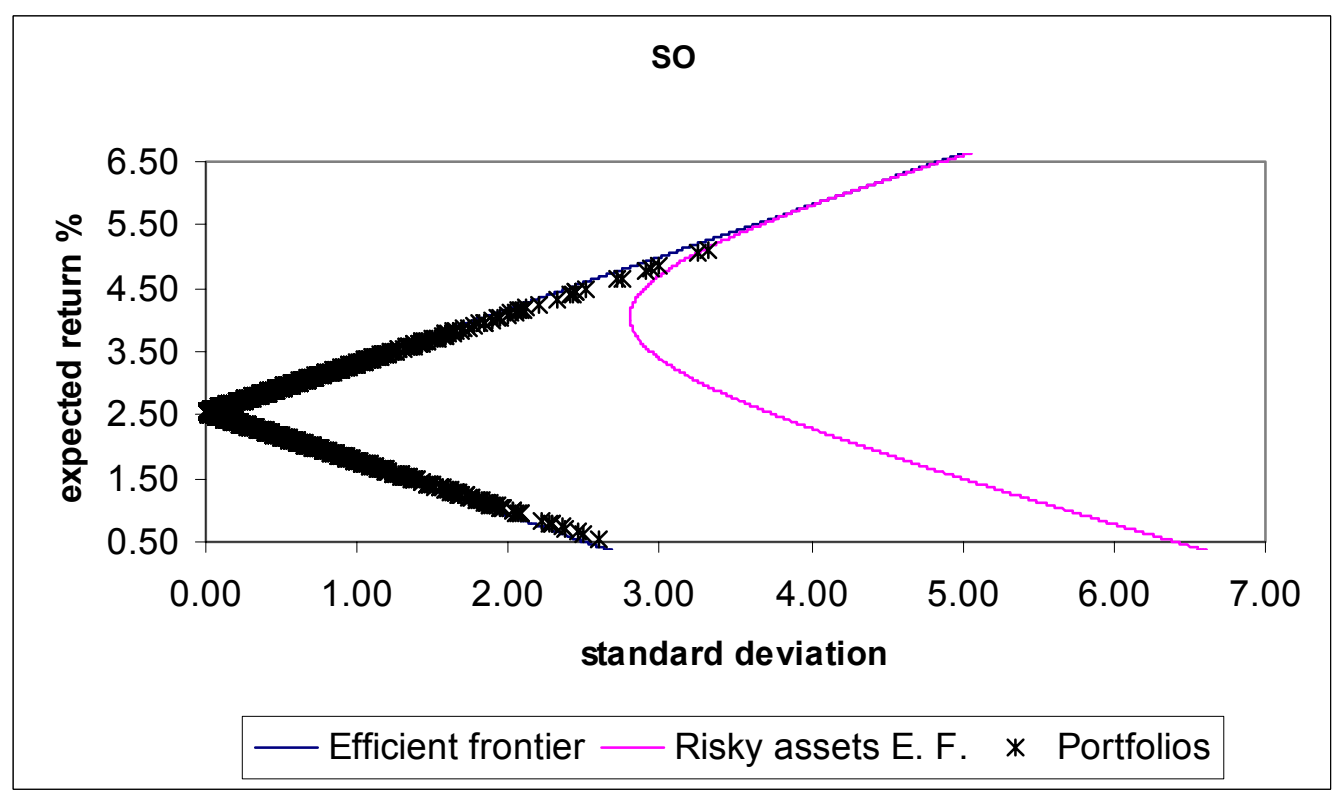


In both Figures 5 and 6, portfolios corresponding to negative net housing positions (the "underhoused") lie on an ascending line that is quite close to the upper part of the broken frontier in the SO and farther away in the NW, but always above the risk-free intercept. Similarly for the overhoused, whose portfolios lie instead on the corresponding descending lines.

This graphical analysis clarifies why the test statistic is very close to zero in the SO, and much higher in the NW, but also suggests the need to consider as inefficient those portfolios that lie below the risk-free intercept even though their test statistic is low.

Hence, in our analysis of diversified portfolios, we shall consider efficiency to be rejected when the test statistic either takes a value higher than the threshold or when the expected return of the hedgeadjusted portfolio is below the risk-free rate. Our graphical analysis of risky portfolios (shown below) shows conclusively that negative excess returns cannot be efficient, given that portfolios with identical standard deviations and higher expected returns are classified as inefficient.

Table 9 reports test results for the sample of well-diversified portfolios, that is for households with some risky financial assets or liabilities. It does so for two different test sizes: In the upper portion of the Table, the chosen test size is $5 \%$; in the lower part, we have set it at $10 \%$.

Table 9. Test results for all households with risky financial assets

\begin{tabular}{|c|c|c|c|c|c|c|c|c|c|c|}
\hline & \multicolumn{2}{|c|}{$\begin{array}{l}\text { Whole country } \\
(\mathbf{N}=2572)\end{array}$} & \multicolumn{2}{|c|}{$\begin{array}{c}\text { NW } \\
(\mathrm{N}=871)\end{array}$} & \multicolumn{2}{|c|}{$\begin{array}{c}\mathbf{N E} \\
(\mathrm{N}=\mathbf{7 0 3}) \\
\end{array}$} & \multicolumn{2}{|c|}{$\begin{array}{c}\text { Centre } \\
(\mathrm{N}=608)\end{array}$} & \multicolumn{2}{|c|}{$\begin{array}{c}\text { South } \\
(\mathbf{N}=390)\end{array}$} \\
\hline & $\mathbf{N}$ & $\%$ & $\mathbf{N}$ & $\%$ & $\mathbf{N}$ & $\%$ & $\mathbf{N}$ & $\%$ & $\mathbf{N}$ & $\%$ \\
\hline \multicolumn{11}{|c|}{ test size $=\mathbf{5 \%}$} \\
\hline Inefficient & 1623 & 62.98 & 636 & 72.94 & 405 & 57.37 & 344 & 56.49 & 238 & 61.03 \\
\hline Efficient & 954 & 37.02 & 236 & 27.06 & 301 & 42.63 & 265 & 43.51 & 152 & 38.97 \\
\hline \multicolumn{11}{|c|}{ test size $=\mathbf{1 0} \%$} \\
\hline Inefficient & 1820 & 70.62 & 714 & 81.88 & 448 & 63.46 & 412 & 67.65 & 246 & 63.08 \\
\hline Efficient & 757 & 29.38 & 158 & 18.12 & 258 & 36.54 & 197 & 32.35 & 144 & 36.92 \\
\hline
\end{tabular}

Depending on the chosen test size, we find that a fraction of $29 \%$ to $37 \%$ of observed portfolios are conditionally efficient overall. There is much regional variability, though, with the lowest proportion of portfolios in the NW that are considered efficient (18\% to $27 \%$ ). 
This is partly due to differences in the partial correlations between housing returns and stocks highlighted in Table 3: as we have already pointed out, for both NW and CE there are large, negative and significant coefficients on stocks. But it also reflects differences in financial investments across regions: as we know, households in the NW (and NE) have the highest investments in stocks. Depending on the housing position, these two factors together play a key role in explaining the efficiency or otherwise of NW and CE household portfolios.

It is useful to see how these proportions vary with net housing wealth. We therefore split the sample in three groups, according to net housing wealth $\left(\mathrm{P}_{0} \mathrm{D}_{0}\right.$ in equation 2$)$. Figure 4 presents a histogram for this variable. We can check that roughly a third of the density lies to the left of $€-$ 50,000 , roughly a third to the right of $€ 50,000$, and the remaining third in between (see the vertical lines in the graph). These proportions are stable across regions, with the only exception of the SO where relatively more observations fall in the middle, and fewer lie to the left of $€-50,000$. Our analysis implies that portfolios of the over-housed should have more in stocks than the Markowitz portfolio, and particularly so in the NW and CE. We find that the proportion of portfolios exceeding $2 \%$ in stocks is indeed higher for the over-housed in the NE (63\%) and SO (36\%), but close to the average in the NW and CE. On the basis of this qualitative analysis, we could conclude that many of the over-housed who invest more than $2 \%$ in stocks could have efficient portfolios, but we need a formal test to support this conjecture. It is in fact worth stressing that the larger the positive net housing position the larger the share in stocks should be - given that financial wealth is a relatively small component of total wealth, households with a large, positive net housing position may well require large investment in stocks to be efficient. 


\section{Figure 4 - Distribution of net housing among households with risky financial assets}

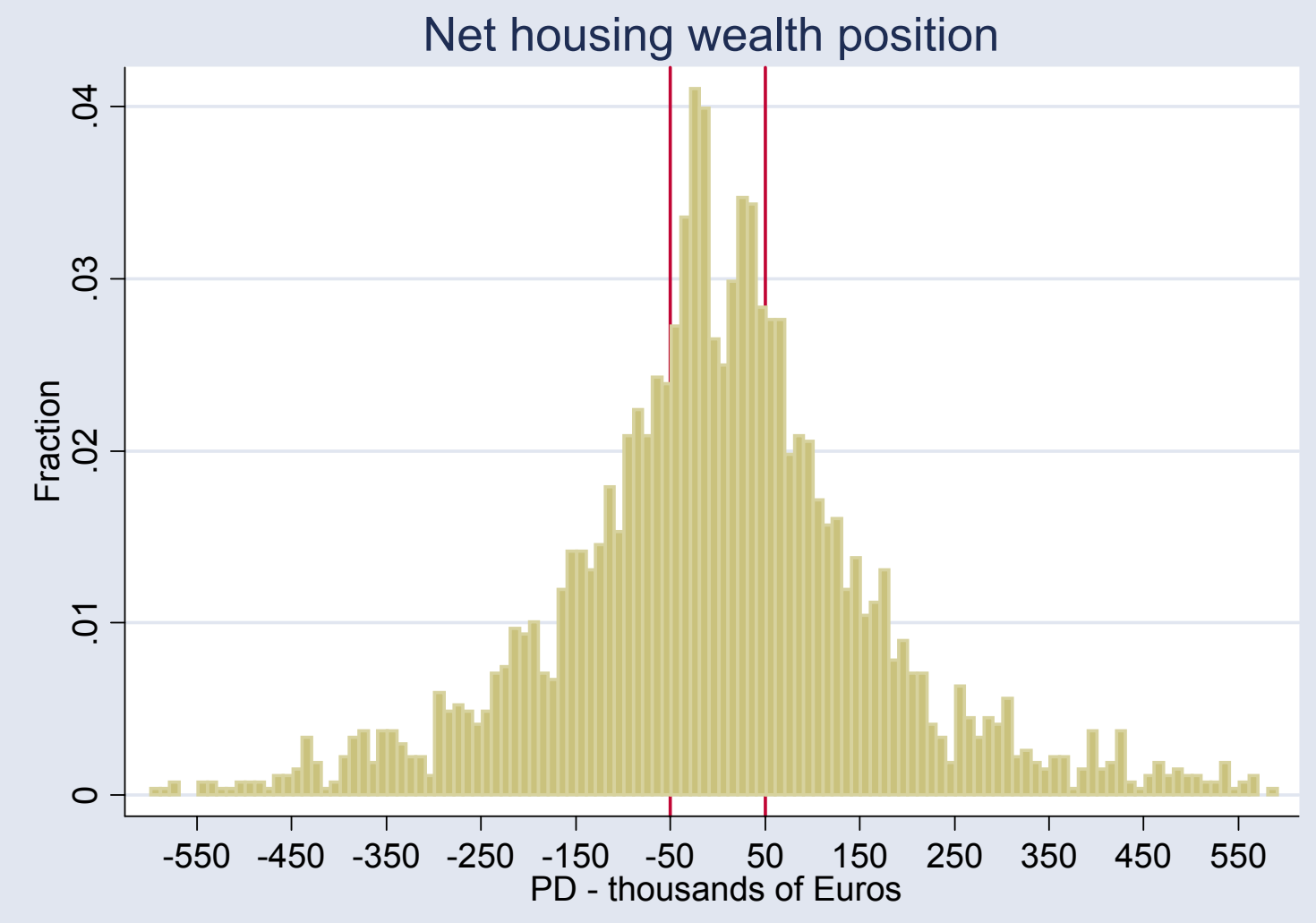

In Table 10 we present the number and fraction of efficient portfolios in each of these three groups (with positive, negligible and negative housing wealth) by broad region. For the sake of simplicity, we report them for just one test size $(5 \%)$.

Table 10. Proportion of efficient portfolios (test size $=5 \%$ ) by net housing position

\begin{tabular}{|l|c|c|c|c|c|c|c|c|c|c|}
\hline & \multicolumn{2}{|l|}{ Whole country } & \multicolumn{2}{c|}{ NW } & \multicolumn{2}{c|}{ NE } & \multicolumn{2}{c|}{ Centre } & \multicolumn{2}{c|}{ South } \\
\hline & $\mathbf{N}^{\circ}$ & $\mathbf{\%}$ & $\mathbf{N}^{\circ}$ & $\mathbf{\%}$ & $\mathbf{N}^{\circ}$ & $\mathbf{\%}$ & $\mathbf{N}^{\circ}$ & $\mathbf{\%}$ & $\mathbf{N}^{\circ}$ & $\mathbf{\%}$ \\
\hline Over-housed & 67 & $\mathbf{7 . 2 0}$ & 30 & $\mathbf{1 0 . 0 0}$ & 16 & $\mathbf{5 . 9 7}$ & 13 & $\mathbf{5 . 7 8}$ & 8 & $\mathbf{5 . 8 0}$ \\
\hline Negligible & 388 & $\mathbf{4 7 . 6 7}$ & 107 & $\mathbf{4 1 . 8 0}$ & 114 & $\mathbf{5 2 . 7 8}$ & 93 & $\mathbf{5 3 . 1 4}$ & 74 & $\mathbf{4 4 . 3 1}$ \\
\hline Under-housed & 499 & $\mathbf{5 9 . 9 8}$ & 99 & $\mathbf{3 1 . 3 3}$ & 171 & $\mathbf{7 7 . 0 3}$ & 159 & $\mathbf{7 6 . 0 8}$ & 70 & $\mathbf{8 2 . 3 5}$ \\
\hline All & 954 & $\mathbf{3 7 . 0 2}$ & 236 & $\mathbf{2 7 . 0 6}$ & 301 & $\mathbf{4 2 . 6 3}$ & 265 & $\mathbf{4 3 . 5 1}$ & 152 & $\mathbf{3 8 . 9 7}$ \\
\hline
\end{tabular}

We see from the last row of Table 10 that 954 well-diversified households have efficient portfolios, that is $37 \%$ of the total. As we have also seen in Table 9, this proportion is highest in the NE and CE (43-44\%), lowest in the NW (27\%). We also see that the highest proportion of efficient portfolios $(60 \%)$ obtains among households who are "under-housed", that is whose net housing position is below $-50,000$. This group includes tenants as well as young home-owners. The lowest 
proportion (7\%) is found among those who are "over-housed" (net housing is larger than 50,000). Among those with intermediate positions ("negligible") the proportion of efficient portfolios are intermediate, but higher than the overall group average. Thus most of the interesting deviations from the overall average are to be found among those with positive net housing wealth, and in the NW broad region.

When we focus on NW households by housing wealth, we find a different pattern: the overall average of $27 \%$ masks a low proportion of efficient portfolios $(10 \%)$ among the positive housing wealth positions, and a much higher one (42\%) among those whose housing position is close to zero. In comparison to other regions, NW over-housed households are more often efficient, the under-housed are less often efficient.

The efficiency pattern is similar to the national average for NE and CE, albeit with fewer overhoused portfolios classified as efficient. In the SO we find a very large fraction of under-housed portfolios efficient. This can be explained by the combination of two factors: the test statistic is very low in the SO for no risky financial assets portfolios (see Figure 6) and even those SO households who invest in risky financial assets have relatively small positions in these assets. ${ }^{5}$

Figures 7 and 8 provide a graphical representation of our efficiency analysis in the mean-standard deviation space for NW and South, where portfolios are expressed net of the hedge term. We split portfolios according to the net-housing position and mark with a darker dot those that we consider efficient.

\footnotetext{
${ }^{5}$ We have checked whether these differences are statistically significant by running a probit regression of the efficiency test outcome on the interactions between housing wealth dummies and broad region dummies, taking as the control group the negligible wealth group in CE. We find strong negative effects for most terms, particularly those involving the NW and the South, with markedly different coefficients across NW variables. We can therefore conclude that the evidence shown in Table 10 is strong despite the relatively small cell sizes.
} 
Figure 7 - Efficiency analysis for the North-West
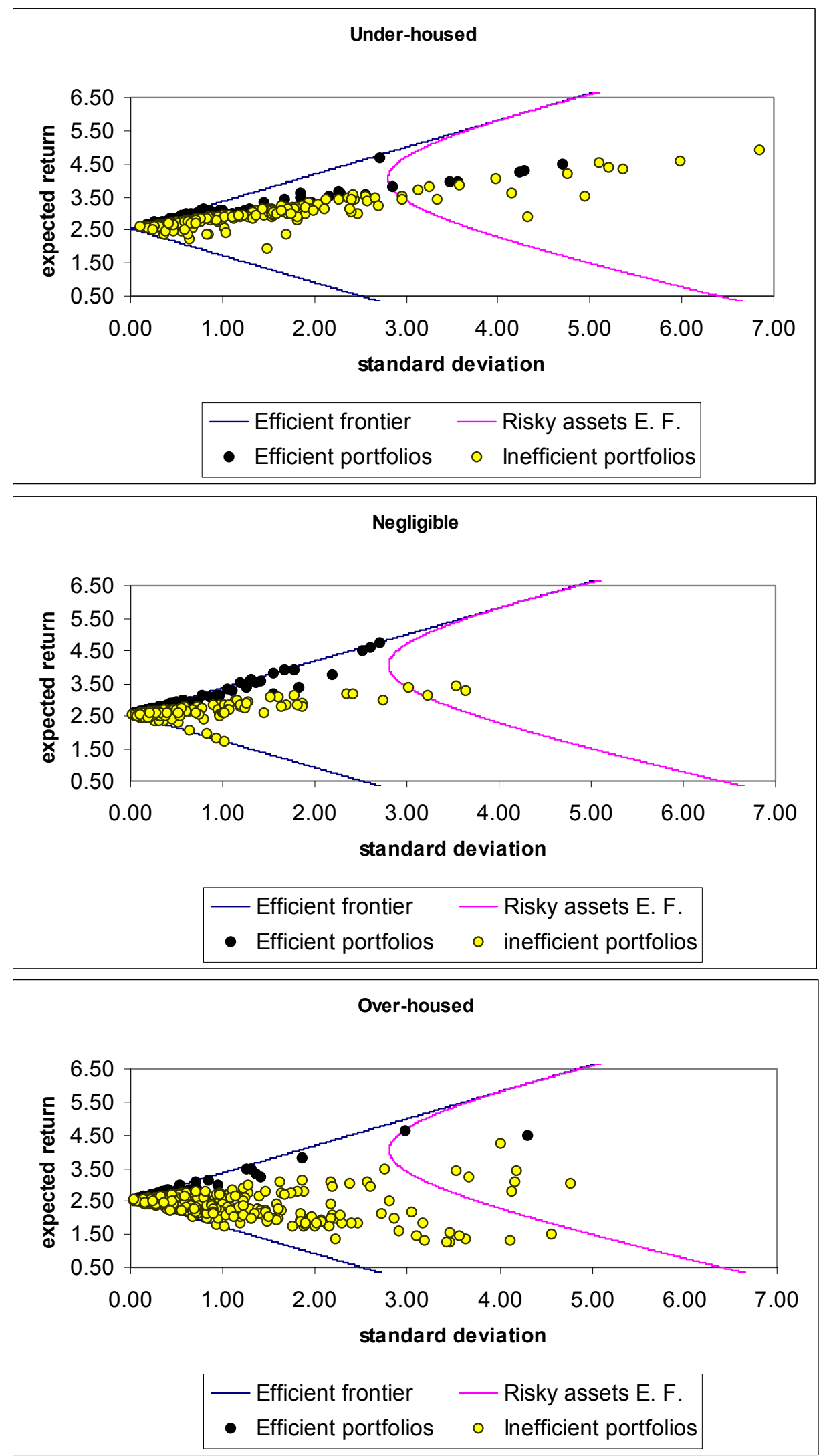
Figure 8 - Efficiency analysis for the South
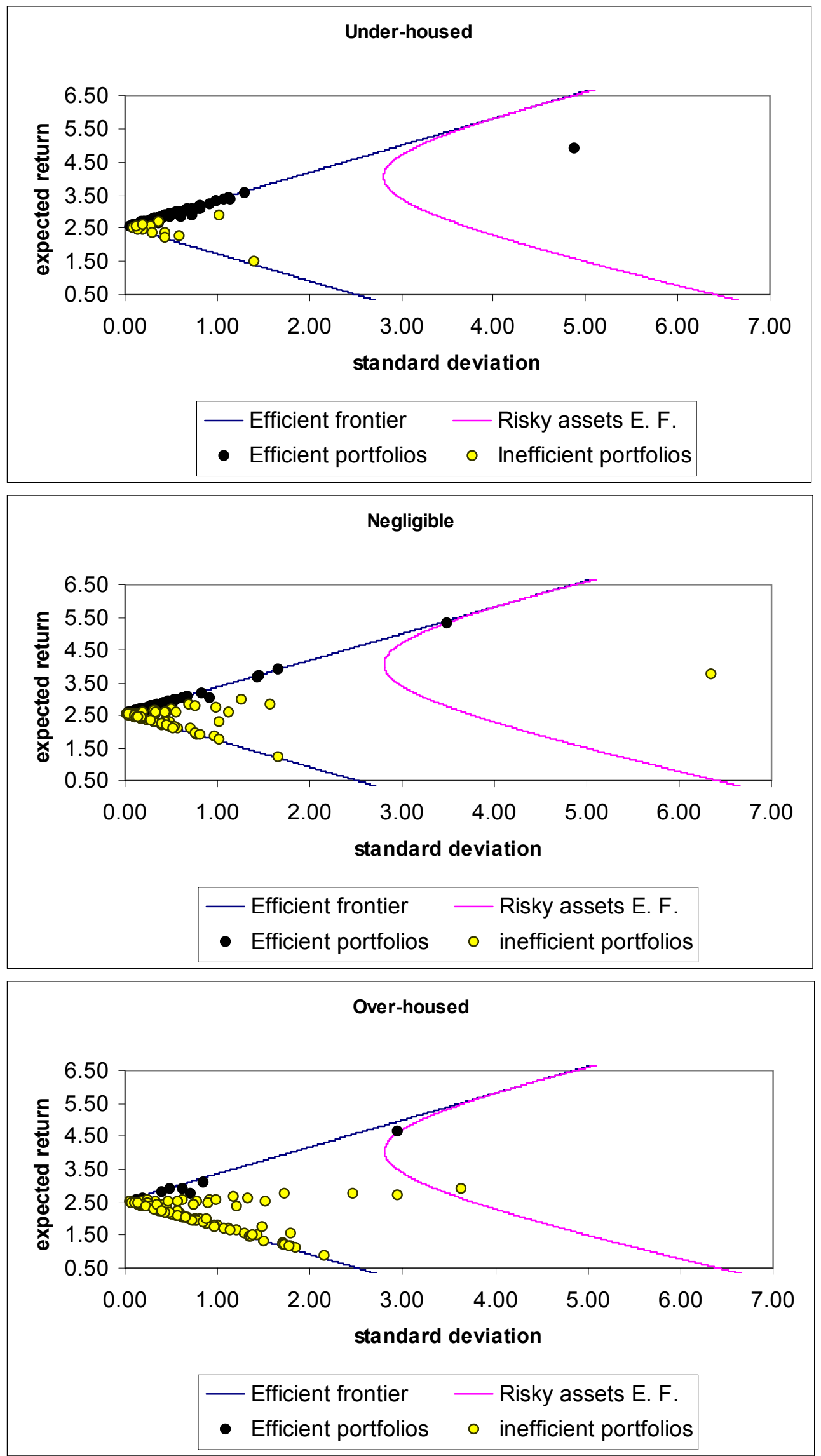
For the under-housed, in all regions many portfolios appear to lie on straight lines, some efficient (see the South), some inefficient (see the NW). These lines are quite similar to those shown in Figures 5 and 6 (no risky assets), and reflect the importance of the hedge term in determining efficiency when risky assets are a relatively small component of wealth. This feature is much less visible for negligible housing positions, because the hedge term plays a much smaller role (it is multiplied by a small number), and for the over-housed, because these households are typically older and richer with larger fractions of wealth invested in risky assets.

For the over-housed, there is a large fraction of portfolios close to the lower branch of the frontier, even though slightly smaller in the NW than in the other regions. This occurs because they are not hedging housing risk: they should hold more stocks (and corporate bonds) than the Markowitz portfolio and do not.

In all regions (but the South) there are non-negligible fractions of portfolios that attain a higher expected return than the risk-free rate but are nonetheless considered inefficient. These are the ones for which it is useful to rely on a formal test statistic. Despite important sampling variability in all moments (first moments of financial assets, second moments of both financial assets and housing), we have seen that the test is able to detect departures from efficiency that are due to incorrect assets allocation.

How important is inefficiency in terms of risk-adjusted returns? After taking out the hedge term, we compute Sharpe ratios for the efficient and for the inefficient. The overall average Sharpe ratio for the efficient is 0.61 , it is -0.15 for the inefficient (who are mostly below the risk-free rate). The Sharpe ratios difference is highest for the over-housed, lowest for the under-housed. A way to evaluate the importance of our findings is to do back-of-the-envelope calculations on the long-term consequences of inefficiency for the over-housed. For this group, inefficiency brings about a loss of 90 basis points for $1 \%$ standard deviation. Over a twenty years time horizon, for every percentage point of risk taken, on average this group loses $20 \%$ of final wealth by failing to hedge housing. 
We also investigate whether and how household characteristics affect portfolio efficiency, after controlling for region and net housing position. In Table 11 we report the results of a probit regression that efficiency is rejected (at 5\%) on the same set of dummy variables described above (corresponding to the different cells in Table 8) and on a few observable characteristics, including head's age, gender and years of education, number of household members (famsize), as well as the total financial wealth to be allocated.

We see from Table 11 that the effects of region interactions with housing position dummies retain their significance, even though the probability of inefficiency is found to be negatively related to education and family size, and positively related to financial wealth.

Table 11. Probit regression of 5\% inefficiency on a number of characteristics (marginal effects)

Probit estimates

Number of obs $=2577$

$\mathrm{LR} \operatorname{chi2}(17)=917.39$

Log likelihood $=-1239.7061$

Prob > chi2 $=0.0000$

Pseudo R2 $=0.2701$

\begin{tabular}{|c|c|c|c|c|c|c|c|}
\hline t95 I & $\mathrm{dF} / \mathrm{d} \mathbf{x}$ & Std. Err. & $\mathbf{z}$ & $\mathrm{P}>|\mathbf{z}|$ & $x$-bar & $95 \%$ & C.I. \\
\hline NW_over* I & -.343318 & .0179386 & -10.25 & 0.000 & .116414 & -.378477 & -.308159 \\
\hline NW_negl*I & -.1052623 & .0379265 & -2.55 & 0.011 & .09934 & -.179597 & -.030928 \\
\hline NW_ūnder* I & -.1685377 & .0343185 & -4.21 & 0.000 & .122623 & -.235801 & -.101275 \\
\hline $\mathbf{N E} \_$over*| & -.3564242 & .0158153 & -10.55 & 0.000 & .103997 & -.387422 & -.325427 \\
\hline NE_negl*i & -.0045194 & .0454503 & -0.10 & 0.921 & .083818 & -.0936 & .084562 \\
\hline NE_ūnder* 1 & .2720772 & .0554489 & 4.97 & 0.000 & .086147 & .163399 & .380755 \\
\hline$C \bar{E} \_$over* $\mid$ & -.3495589 & .0152234 & -10.02 & 0.000 & .087311 & -.379396 & -.319722 \\
\hline CE_ünder* I & .2843184 & .0550923 & 5.20 & 0.000 & .081102 & .176339 & .392297 \\
\hline sōover*1 & -.3262791 & .0158361 & -7.97 & 0.000 & .053551 & -.357317 & -.295241 \\
\hline So_negl*1 & -.0488057 & .0459757 & -1.03 & 0.305 & .064804 & -.138916 & .041305 \\
\hline so_under* I & .3833048 & .0684051 & 5.17 & 0.000 & .032984 & .249233 & .517376 \\
\hline - age I & .0011872 & .0019525 & 0.61 & 0.543 & 55.5165 & -.00264 & .005014 \\
\hline$(\text { age }-40)^{2} \mid$ & -.0000635 & .0000521 & -1.22 & 0.222 & 428.321 & -.000166 & .000039 \\
\hline male* & -.0250597 & .0234574 & -1.08 & 0.282 & .712068 & -.071035 & .020916 \\
\hline famsize | & -.0363759 & .0101903 & -3.57 & 0.000 & 2.81102 & -.056348 & -.016403 \\
\hline educ i & -.0093951 & .0029254 & -3.21 & 0.001 & 10.104 & -.015129 & -.003661 \\
\hline f_wealth | & .0006659 & .0001211 & 5.47 & 0.000 & 46.5295 & .000428 & .000903 \\
\hline
\end{tabular}

The effect of the head's age is non-linear: the probability of inefficiency increases with age until age 70 , it decreases thereafter.

We can check whether our results depend on the ad-hoc simplifying assumptions made on human capital, particularly on the rate used to discount future earnings and pension benefits, and on its 
risk-free nature. When we increase the discount rate for human capital by a third, the efficiency test results are only marginally affected. When we take the self-employed out of the analysis, the patterns highlighted above remain valid.

\section{Robustness analysis}

In Section 3 we presented results based on a number of assumptions, some of which we can relax. In this section, we show how our results are affected when we:

a) allow human capital to be risky for working-age households;

b) assume less than unit correlation between the housing service price (rent) changes and house price changes, i.e. owning is less than a perfect hedge against rent risk;

c) allow households to invest in foreign as well as domestic assets;

d) allow for non-negativity constraints;

e) consider a range of different parameter estimates of the stock exchange parameter in the housing return equation.

\subsection{Risky human capital}

Our theoretical and empirical analysis has so far treated human capital returns as risk-free. This assumption is of course very strong, but it can be relaxed if we are prepared to treat human capital like housing wealth, that is given in the short run. In this case our conditional analysis requires conditioning on two assets, and equation (2) becomes:

$$
\underline{X}_{0}^{* T}=\left[\frac{-\frac{\partial V}{\partial T W}}{\frac{\partial^{2} V}{\partial T W^{2}}}\right] \Sigma^{-1} \underline{\mu}^{T}-P_{0} D_{0} \Sigma^{-1} \Gamma_{b P}^{T}-H C_{0} \Sigma^{-1} \Gamma_{b H C}^{T}
$$

Where $\mathrm{HC}_{0}$ is the current value of human capital and $\Gamma_{b H C}^{T}$ denotes the vector of covariances between human capital return and financial assets. The intuition behind equation (8) is straightforward: optimal portfolios are made of the Markowitz portfolio, net of two hedge terms, one for housing, the other one for human capital. 
The test statistic is computed as in equation (5), once $\Omega$ and $\mathrm{Z}$ are redefined to include the extra given asset, human capital.

The more difficult task is to find good estimates of human capital returns. In principle, one should use panel data spanning a long period and recording hourly wages at a suitable frequency (semiannual or higher). To our knowledge, such data do not exist for Italy (SHIW has a small panel component, but the survey takes places at 2-3 years intervals). Given the exploratory nature of this robustness exercise, we decided to use aggregate data on earnings per employee, and to remove the effects of work-force aging by taking the residuals of semi-annual changes in the logarithm of earnings per employee on a deterministic trend.

The resulting annual excess return has a negative sample mean $(-0.6 \%)$ and a relatively low standard deviation (2.43\%). It exhibits negative correlations with all three financial assets: -.21 with Government Bonds, -. 17 with stocks and -.01 with corporate bonds. Its correlation with housing is positive (.61), even though this is irrelevant for our analysis. The regression of human capital return on a constant and the three financial asset returns produces the following estimates:

$$
\begin{aligned}
r_{t}^{H C}= & 0.614-0.425 r_{t}^{G}+0.450 r_{t}^{C}-0.025 r_{t}^{S} \\
& (0.29) \quad(0.14) \quad(0.25)
\end{aligned}
$$

There is a strong negative relation with Government Bonds, positive with Corporate Bonds, and a smaller, but marginally significant, negative relation with stocks.

Equation (9) provides both the weights of the second hedge portfolio in (3), and the discount rate to be used to compute, for each household, an estimate of HC. Based on sample means of the three financial asset returns, and the observed risk free rate at the end of 2002, we can compute the nominal return implied by the model. Once we subtract $1.5 \%$ inflation, we obtain a real annual discount rate of $1.39 \%$. We apply this discount rate to all labor income, including self-employment income, but note that this may bias HC upwards for the self-employed (whose income may be 
riskier than earnings). We treat $\mathrm{HC}$ as risk-free for the retired (that is, for all households whose head is 60 or more), given that pension income is price inflation-index in Italy.

Table 12: Amounts held in financial and real assets when human capital is risky

\begin{tabular}{|l|c|c|c|}
\hline Asset & $\begin{array}{c}(\mathbf{1}) \\
\text { Average }\end{array}$ & $\begin{array}{c}\mathbf{( 2 )} \\
\text { Median }\end{array}$ & $\begin{array}{c}\mathbf{( 3 )} \\
\text { Conditional Average }\end{array}$ \\
\hline Total Financial Assets & $\mathbf{2 3 , 4 8 2}$ & $\mathbf{7 , 2 5 0}$ & $\mathbf{4 6 , 7 0 9}$ \\
\hline Housing & 132,853 & 100,000 & 204,110 \\
\hline Present Value of Rents & 141,988 & 99,985 & 186,417 \\
\hline Human Capital & 436,413 & 333,611 & 579,850 \\
\hline Total Wealth & $\mathbf{4 4 7 , 4 6 5}$ & $\mathbf{3 3 7 , 2 7 8}$ & $\mathbf{6 6 3 , 9 6 0}$ \\
\hline
\end{tabular}

Note: number of observations in columns (1) and (2) =7457; in column (3): 2577

In Table 12 - that compares directly to Table 5 - we show the average, median and conditional average of the new human capital variable, as well as of total financial assets and total wealth. Even though human capital has been reduced by some $10 \%$ on average, it remains by far the largest component of total wealth. In the more interesting case of households owning some financial risky asset (column 3), we find that human capital is smaller than housing in 349 cases (one in seven), it is smaller than net housing wealth in just 187 cases (one in thirteen): these households tend to be older than the rest of the sample (on average by 10 and 15 years, respectively).

In Table 14 we show how many portfolios are efficient by region and net-housing position - the table compares directly to Table 8 in Section 3 . When we look at the country as a whole, we notice a much lower number of efficient portfolios (529 instead of 954). This is also true for the underhoused (272 instead of 499) and for those with negligible housing position (178 instead of 388). The over-housed, instead, appear more often efficient (99 instead of 67).

To understand these patterns, we note that the presence of the human capital hedge shown in equation (9) implies that households with negligible housing positions should increase their shares of government bonds and (to a lesser extent) stocks, and decrease their share of corporate bonds. Given that the tangency portfolio already has a very large share of government bonds, investing even more in such bonds may be hard. Also, the relatively small coefficient on shares has to be 
compared the similarly small share of stocks in the tangency portfolio $(2 \%)$. Given that few households have large stock positions, the overall fall in efficiency comes as no surprise.

The reason why efficiency decreases most for the under-housed, least for the over-housed, is because the under-housed are young and therefore have more human capital: they should increase Government Bond holdings most, and avoid (fixed-interest) mortgages. The over-housed, instead, have lower human capital, little or no mortgages, and have higher holdings of Government Bonds and Stocks. To the extent that our measure of human capital risk is appropriate for them, they tend to do the right thing more often than the under-housed.

Table 13. Proportion of efficient portfolios by net housing position when human capital is risky for workers (test size $=\mathbf{5 \%}$ )

\begin{tabular}{|l|c|c|c|c|c|c|c|c|c|c|}
\hline & \multicolumn{2}{|c|}{$\begin{array}{c}\text { Whole } \\
\text { country }\end{array}$} & \multicolumn{2}{|c|}{ NW } & \multicolumn{2}{c|}{ NE } & \multicolumn{2}{c|}{ Centre } & \multicolumn{2}{c|}{ South } \\
\hline & $\mathbf{N}^{\circ}$ & $\%$ & $\mathbf{N}^{\circ}$ & $\%$ & $\mathbf{N}^{\circ}$ & $\%$ & $\mathbf{N}^{\circ}$ & $\%$ & $\mathbf{N}^{\circ}$ & $\%$ \\
\hline Over-housed & 99 & $\mathbf{1 0 . 6 5}$ & 30 & $\mathbf{1 0 . 0 0}$ & 26 & $\mathbf{9 . 7 4}$ & 23 & $\mathbf{1 0 . 2 2}$ & 20 & $\mathbf{1 4 . 4 9}$ \\
\hline Negligible & 272 & $\mathbf{3 3 . 4 1}$ & 88 & $\mathbf{3 4 . 5 1}$ & 59 & $\mathbf{2 7 . 5 7}$ & 54 & $\mathbf{3 0 . 8 6}$ & 71 & $\mathbf{4 2 . 2 6}$ \\
\hline Under-housed & 178 & $\mathbf{2 1 . 3 9}$ & 57 & $\mathbf{1 7 . 9 8}$ & 40 & $\mathbf{1 8 . 1 8}$ & 52 & $\mathbf{1 5 . 6 1}$ & 29 & $\mathbf{3 4 . 1 2}$ \\
\hline All & 529 & $\mathbf{2 0 . 5 2}$ & 175 & $\mathbf{2 0 . 0 7}$ & 125 & $\mathbf{1 7 . 8 3}$ & 109 & $\mathbf{1 8 . 0 2}$ & 120 & $\mathbf{3 0 . 6 9}$ \\
\hline
\end{tabular}

We should stress that these results are not driven by the low return on human capital implied by equation (9): even if we assume human capital return to be much higher (4\%), and discount future incomes accordingly, we find that the number of efficient portfolios is largely the same as shown in Table 13.

We conclude from this analysis that the risky nature of human capital may have important consequences for portfolio efficiency.

\subsection{Owning is a less than perfect hedge against rent risk}

In Section 3 we have considered the case where owning is a perfect hedge against rent risk, because the price of housing services has unit correlation with house prices. This case is appealing in the long run (when rents are roughly proportional to house values), but obviously not necessarily true in the short or even medium run. Here we consider what happens to our efficiency analysis when the correlation between house price changes and rental price changes is not perfect, but varies between 
one (as in Section 3) and zero. This last case is analyzed in some recent papers that ignore the liability side of housing (Flavin and Yamashita, 2002, Cocco, 2005 and Pelizzon and Weber, 2006).

Figure 9 shows the proportions of efficient portfolios for the three net-housing groups considered so far as a function of $\beta_{P \pi}$, the hedge ratio between house returns and rents (see the Appendix). We should stress that we keep the groups' composition constant in this comparison, even though their net housing value (defined as value of the house minus $\beta_{P \pi}$ times the present value of rents) changes - in other terms, net housing positions are defined once and for all with reference to the case where $\beta_{P \pi}=1$.

We see from Figure 9 that the over-housed appear mostly inefficient for any beta. This is not surprising: the reason why they are inefficient for $\beta_{P \pi}=1$ is that they do not hedge their positive housing position. Taking lower values of beta implies even larger positive housing positions, and efficiency is even less often achieved.

Efficiency results also deteriorate going from right to left for the other two groups, whose net housing position becomes less negative and then positive when beta approaches zero, as long as they own at all. For renters instead net housing never becomes positive, and when $\beta_{P \pi}=0$ the analysis collapses to the standard efficiency analysis of financial portfolios.

Housing wealth plays a role for all three groups and this explains why the lines do not appear to converge as $\beta_{P \pi}$ approaches zero.

Overall the analysis shows that housing needs plays an important role for portfolio efficiency and ignoring this aspect induces an over-estimation of portfolio inefficiency. 


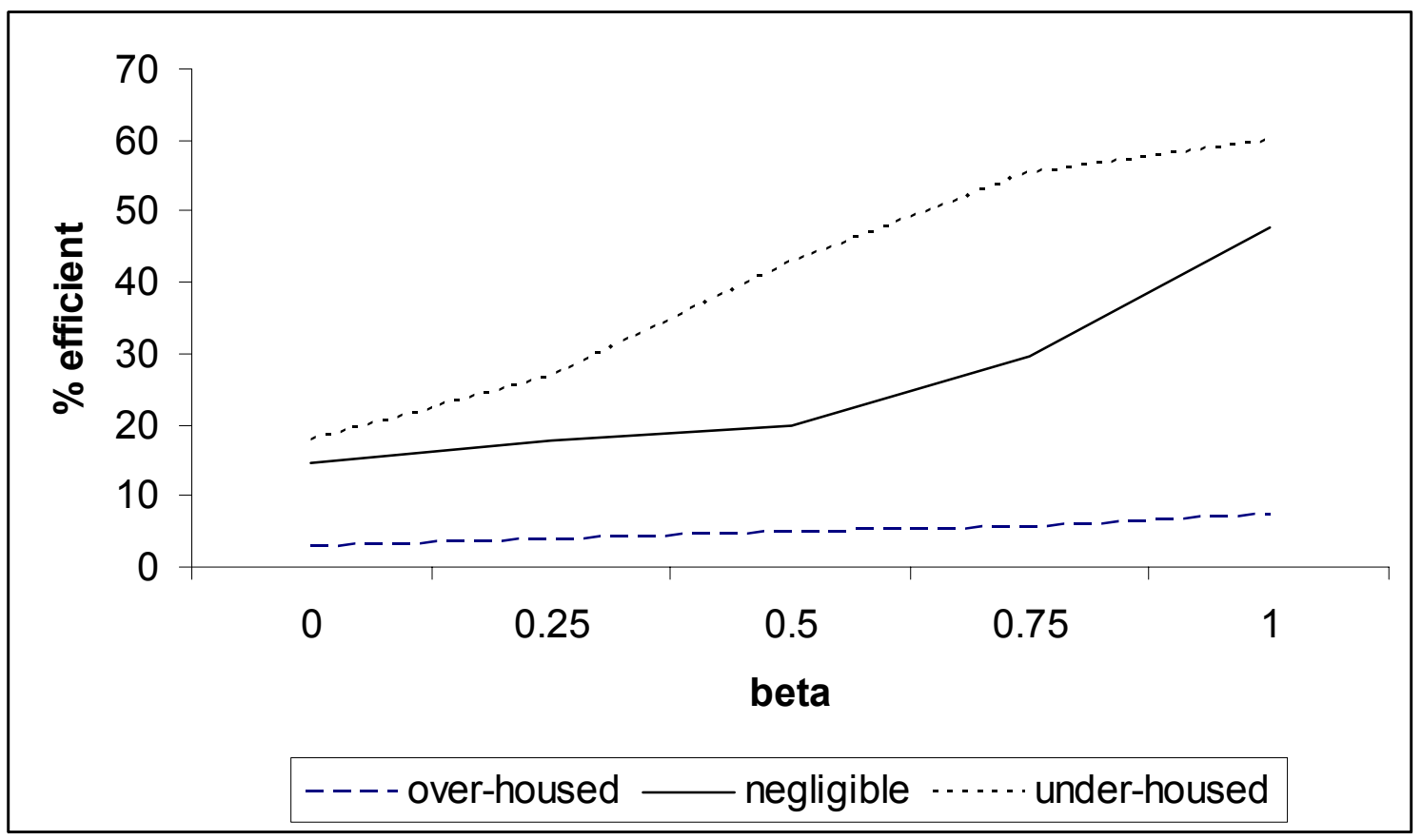

\subsection{International portfolio diversification}

In Section 3 we have assumed that Italian households invest in domestic stocks and bonds. This is particularly problematic for indirect holdings of stocks: we know from financial industry sources (Assogestioni) that in 2002 Italian mutual funds stock investment were three quarters in foreign stocks, one quarter in domestic stocks. According to a different source, the Bank of Italy financial statistics, roughly $50 \%$ of stocks were from Euro-area markets. Finally, we know that direct and indirect stock market participation were similar in 2002 (see Table 4), and this is also true for average amounts in our sample. Direct holdings are almost exclusively concentrated in domestic stocks.

Based on this information, we checked whether our analysis is robust to assuming that stock holdings were split among domestic stocks (62\%) and foreign stocks (32\%), and used MSCI Italy and MSCI world returns to compute their returns. We denote this asset as "international stocks".

In Tables 14 and 15 we report descriptive statistics of the resulting returns. Compared to Table 1, we see from Table 14 that international stocks have lower expected returns (3.96\% versus $4.90 \%)$ and lower standard deviation (27.65\% instead of $28.99 \%)$. Remarkably, they have a negative 
correlation with government bonds return: this insurance property implies that optimal stock holdings are higher than in the case previously considered.

Table 14 - Sample first and second moments of annual excess returns

\begin{tabular}{|c|c|c|c|}
\hline & $\begin{array}{c}\text { Government } \\
\text { Bonds }\end{array}$ & $\begin{array}{c}\text { Corporate } \\
\text { Bonds }\end{array}$ & $\begin{array}{c}\text { International } \\
\text { Stocks }\end{array}$ \\
\hline Expected return \% & 4.0981 & 2.2845 & 3.9649 \\
\hline Standard Deviation \% & 5.2383 & 3.2169 & 27.6519 \\
\hline
\end{tabular}

\begin{tabular}{|c|c|c|c|}
\hline CORRELATION & $\begin{array}{l}\text { Government } \\
\text { Bonds }\end{array}$ & $\begin{array}{l}\text { Corporate } \\
\text { Bonds }\end{array}$ & Stocks \\
\hline Government Bonds & 1 & 0.8404 & -0.0981 \\
\hline Corporate Bonds & & 1 & 0.0565 \\
\hline International Stocks & & & 1 \\
\hline
\end{tabular}

Table 15 - Correlation matrix of housing and financial returns

\begin{tabular}{|c|c|r|r|r|}
\hline & \multicolumn{1}{|c|}{$\boldsymbol{N W}$} & \multicolumn{1}{c|}{ NE } & \multicolumn{1}{c|}{ Centre } & \multicolumn{1}{c|}{ South } \\
\hline Government bonds & -0.0164 & -0.1169 & -0.1161 & -0.2036 \\
\hline Corporate bonds & -0.0843 & -0.1691 & -0.2177 & -0.1998 \\
\hline International Stocks & -0.5432 & -0.3660 & -0.4484 & -0.1959 \\
\hline
\end{tabular}

Table 16 - Regression of excess return on housing on financial assets excess returns

\begin{tabular}{|ccccc|}
\hline Variable & North West & North East & Centre & South \\
\hline Constant & 2.7403 & 2.894 & 2.8884 & 2.8548 \\
& $(0.5259)$ & $(0.5618)$ & $(0.7110)$ & $(0.5534)$ \\
r $_{\text {GOv. }}$ & -0.0739 & -0.0289 & 0.0536 & -0.1929 \\
& $(0.2666)$ & $(0.284)$ & $(0.3595)$ & $(0.2798)$ \\
r CORP & -0.2896 & -0.4414 & -0.7547 & -0.3313 \\
r $_{\text {STOCKS }}$ & $(0.4454)$ & $(04758)$ & $(0.6021)$ & $(0.4686)$ \\
& -0.1146 & -0.0678 & -0.1049 & -0.0409 \\
\hline p-value & $(0.0284)$ & $(0.0304)$ & $(0.0384)$ & $(0.0299)$ \\
$\mathbf{R}^{2}$ & 0.000 & 0.009 & 0.006 & 0.007 \\
& 0.576 & 0.416 & 0.436 & 0.433 \\
\hline
\end{tabular}

Notes: Standard errors in parentheses. Number of observations $=28$

The efficiency portfolio has weights of .67 on government bonds, .29 on corporate bonds and .04 on stocks - this compare to $.63, .35$ and .02 of the domestic stock return case. Table 15 however shows that correlation coefficients with housing are quite similar, and this results in minor changes in the regression coefficients (see Table 16). 
In Table 17 we present the number and fraction of efficient portfolios in each net-housing group by broad region. A comparison with Table 8 shows that there are remarkably little differences.

Table 17 - Proportion of efficient portfolios (test size 5\%) by net housing position

\begin{tabular}{|l|c|c|c|c|c|c|c|c|c|c|}
\hline & \multicolumn{2}{|c|}{ Whole country } & \multicolumn{2}{|c|}{ NW } & \multicolumn{2}{c|}{ NE } & \multicolumn{2}{c|}{ Centre } & \multicolumn{2}{c|}{ South } \\
\hline & $\mathbf{N}^{\circ}$ & $\mathbf{\%}$ & $\mathbf{N}^{\circ}$ & $\mathbf{\%}$ & $\mathbf{N}^{\circ}$ & $\mathbf{\%}$ & $\mathbf{N}^{\circ}$ & $\%$ & $\mathbf{N}^{\circ}$ & $\%$ \\
\hline Over-housed & 56 & $\mathbf{6 . 0 1}$ & 28 & $\mathbf{9 . 2 7}$ & 14 & $\mathbf{5 . 2 2}$ & 8 & $\mathbf{3 . 5 7}$ & 6 & $\mathbf{4 . 3 5}$ \\
\hline Negligible & 372 & $\mathbf{4 5 . 7 6}$ & 102 & $\mathbf{3 9 . 8 4}$ & 104 & $\mathbf{4 8 . 6 0}$ & 96 & $\mathbf{5 4 . 8 6}$ & 70 & $\mathbf{4 1 . 6 7}$ \\
\hline Under-housed & 525 & $\mathbf{6 2 . 5 0}$ & 126 & $\mathbf{3 9 . 5 0}$ & 166 & $\mathbf{7 4 . 1 1}$ & 164 & $\mathbf{7 7 . 3 6}$ & 69 & $\mathbf{8 1 . 1 8}$ \\
\hline All & 953 & $\mathbf{3 6 . 8 7}$ & 256 & $\mathbf{2 9 . 1 9}$ & 284 & $\mathbf{4 0 . 2 3}$ & 268 & $\mathbf{4 3 . 8 6}$ & 152 & $\mathbf{3 8 . 8 7}$ \\
\hline
\end{tabular}

\subsection{Non-negativity constraints}

Our analysis neglects the issue of short-selling constraints: in our model households can take negative positions on stocks, and their housing-related liabilities can exceed the value of their housing stock. If actual households are subject to non-negativity constraints on stocks, and if their net positions on bonds cannot exceed their housing value, then their feasible efficiency frontier will lie below the frontier we have considered. This may imply that some portfolios that we consider inefficient are instead efficient.

This issue is of particular concern in our case, where we analyze conditional efficiency, because the hedge term in equation (2) may imply that the optimal portfolio itself violates these constraints. For those households whose optimal portfolio violates non-negativity constraints our analysis should not be applied.

Let us re-write equation (2) in portfolio share terms:

$$
\frac{\underline{X}_{0}^{* T}}{T W}=\left[\frac{-\frac{\partial J}{\partial T W}}{\frac{\partial^{2} J}{\partial T W^{2}}}\right] \frac{1}{T W} \Sigma^{-1} \underline{\mu^{T}}-P_{0} D_{0} \Sigma^{-1} \Gamma_{b P}^{T}=\alpha \Sigma^{-1} \underline{\mu^{T}}-P_{0} D_{0} \Sigma^{-1} \Gamma_{b P}^{T}
$$

where $\alpha$ is one over the relative risk aversion parameter. In this context, the optimal portfolio depends on risk aversion. If we are prepared to assume that relative risk aversion takes a unit value 
(as in the standard log utility case), then we can derive the optimal portfolio for each value of the net housing position, and find out for which households negativity constraints are violated.

We find that in total 908 households have optimal portfolios that violate non-negativity constraints (when $\alpha=1$ ): 379 in the North-West, 215 in the Centre, 257 in the North-East and just 57 in the South. Almost all these households (752 out of 908) are under-housed - this is not surprising, because the under-housed should hedge their net housing risk by holding negative positions on stocks, as shown in Table 7.

Given that the under-housed hold the largest fraction of efficient portfolios (almost 60\%) even when we neglect the non-negativity constraints; we conclude that this type of constraints is not responsible for the common occurrence of inefficient portfolios.

\subsection{Sensitivity analysis}

The hedge term parameters in equation (2) are based on estimated parameters of the regressions of excess return on housing on financial assets excess returns for each macro region, and are shown in Table 3. The test procedure takes into account sampling variability in these estimates, but still uses the specific estimated values. The fact that the sample period is relatively short, and the sampling frequency is low, implies that the estimated parameters have large confidence intervals.

Unfortunately these confidence intervals cannot be narrowed easily, because of data limitations. The low frequency is dictated by the workings of the housing market, where volumes are sufficiently high twice a year (Spring and Autumn) - the relatively short period is instead due to the relatively recent introduction of government bonds in Italy.

What we can do is to check how our efficiency analysis would change if the parameters where at the extremes of their confidence interval. Given the key role played by stocks, we shall concentrate on this particular parameter, keeping all remaining parameters at their point estimates. 
Table 18 - Proportion of efficient portfolios (test size 5\%) by net housing position, for different values of the stock coefficient

\begin{tabular}{|l|c|c|c|c|c|c|c|c|c|}
\hline & \multicolumn{3}{|c|}{ NW (N=871) } & \multicolumn{3}{c|}{ NE (N=703) } & \multicolumn{3}{c|}{ CE (N=608) } \\
\hline $\begin{array}{l}\text { Coefficient } \\
\text { on stock }\end{array}$ & $\mathbf{- . 0 4 1 9}$ & $\mathbf{- . 0 9 6 8}$ & $\mathbf{- . 1 5 1 7}$ & $\mathbf{. 0 1 5 2}$ & $\mathbf{- . 0 4 2 7}$ & $\mathbf{- . 1 0 1 5}$ & $\mathbf{- . 0 1 1 1}$ & $\mathbf{- . 0 8 4 4}$ & $\mathbf{- . 1 5 7 7}$ \\
\hline Over-housed & 47 & $\mathbf{3 0}$ & 29 & 22 & $\mathbf{1 6}$ & 28 & 21 & $\mathbf{1 3}$ & 7 \\
\hline Negligible & 132 & $\mathbf{1 0 7}$ & 87 & 127 & $\mathbf{1 1 4}$ & 72 & 95 & $\mathbf{9 3}$ & 75 \\
\hline Under-housed & 227 & $\mathbf{9 9}$ & 30 & 189 & $\mathbf{1 7 1}$ & 97 & 173 & $\mathbf{1 5 9}$ & 35 \\
\hline All & 406 & $\mathbf{2 3 6}$ & 146 & 338 & $\mathbf{3 0 1}$ & 206 & 305 & $\mathbf{2 6 5}$ & 117 \\
\hline
\end{tabular}

In table 18 we show the number of efficient portfolios for three macro-regions (the fourth, South, is almost completely unaffected) when we perturbate the stock coefficient: for each region, we consider the point estimate (centre), the upper bound of the $95 \%$ confidence interval (left), and the lower bound of the $95 \%$ confidence interval (right). The middle column corresponds to Table 8 .

In the case of the NW, the highest value taken by the coefficient is negative but about one half in absolute value than the point estimate. The number of efficient portfolios is much higher (406 instead of 236), and this increase is mostly accounted for by the under-housed. When we consider the lowest possible value of the coefficient, results are reversed: only 146 portfolios are efficient, and only 30 among the under-housed. The number of efficient portfolios among the over-housed is consistently low for all three values of the parameter.

In the case of the NE, the stock coefficient is sufficiently close to zero that the confidence interval crosses the zero line. So the highest value we consider is positive, while the lowest is negative and close in size to the point estimate for the NW. The number of efficient portfolios is very close between the first two columns, while the right column produces a pattern of efficiency quite close to the NW mid-range case.

In the last three columns, we show the number of efficient portfolios in the Center macro-region. In this case, all three values of the coefficient are negative, but the difference between the middle and the left column is relatively minor. The right column, corresponding to a very low value of the coefficient, shows a marked decline in the number of efficient portfolios (only negligible positions appear efficient). 
Overall we have that the number of efficient portfolios changes if we allow the stock coefficient to takes values at the boundary of its confidence interval, but the qualitative result that efficiency is largely driven by net housing positions is not affected.

\section{Conclusions}

In this paper we have investigated how portfolio choices should be taken when housing represents a perfect hedge for rent risk. We have argued that in this case future rents are a stochastic liability. In this asset-liability framework the relevant housing wealth concept is the difference between the market value of housing stock owned and the present discounted value of current and future housing needs. Under the assumption that main residence housing consumption equals housing needs, the present value of housing needs can be calculated from micro data on rents (actual for tenants, imputed or self-assessed for owner-occupiers).

According to our model, households are short on housing ("under-housed") when they either rent or own dwellings that are small compared to their future needs. Households who are owner occupiers may be long on housing ("over-housed") at a late stage in the life cycle, when their future housing needs are declining and their death probability is increasing. However, long positions can also be obtained by purchasing secondary or investment homes. The under-housed are more exposed to rent risk, the over-housed (who are interested in the liquidation value of their home) to house price risk. In order to evaluate the empirical relevance of housing risk in household portfolios, we have shown how optimal portfolios should be when housing returns correlate with financial returns as they do in Italy, and compared the efficiency of financial asset allocations for Italian households who are overhoused, under-housed or who have negligible housing positions. This comparison is of particular interest for financial intermediaries who design and sell securities to the general public, but is also of interest for its economic and policy implications.

Our key result is that many households do not appear to hedge housing risk in a satisfactory way. We have shown that the largest fraction of efficient financial portfolios is found among households 
who are "under-housed", and should have less in stocks than the standard Markowitz portfolio. The smallest fraction of efficient portfolios obtains among households who are "over-housed": even though in this group there is the highest proportion of stock-owners, their investment in stocks is often not sufficient to hedge all the housing risk. 


\section{References}

Anderson, Ronald W., and Jean-Pierre Danthine (1981) 'Cross Hedging', Journal of Political Economy, 89(6), 1182-96

Attanasio, Orazio P., James Banks, Costas Meghir and Guglielmo Weber (1999) 'Humps and Bumps in Life-Time Consumption', Journal of Business and Economic Statistics, 17(1), 22-35

Banks, James, Richard Blundell, Zoe Oldfield and James P. Smith (2004) 'Housing Wealth over the Life-Cycle in the Presence of Housing Price Volatility', Institute for Fiscal Studies, mimeo (September)

Barberis, Nicholas (2000) "Investing for the Long Run when Returns are Predictable", Journal of Finance 55, 225-264.

Biancotti, Claudia, Giovanni D'Alessio, Ivan Faiella and Andrea Neri (2004) 'Italian Household Budgets in 2002', Supplements to Statistical Bulletin, Methodological Notes and Statistical Information, no. 14(12), Rome: Banca d'Italia (available at http://www.bancaditalia.it ).

Bodie, Zvi, Robert C. Merton and William F. Samuelson (1992) 'Labor Supply Flexibility and Portfolio Choice in a Life Cycle Model', Journal of Economic Dynamics and Control, 16, 427-499.

Brugiavini, Agar and Elsa Fornero (2001) 'Pension Provision in Italy', in Richard Disney and Paul Johnson (eds.) Pension Systems and Retirement Income across OECD Countries, London: Edward Elgar, 197-231

Campbell, John Y., and Luis M. Viceira (2002) Strategic Asset Allocation - Portfolio Choice for Long-Term Investors, Oxford: Oxford University Press.

Campbell, John Y., and Luis M. Viceira (2005) 'Strategic Asset Allocation for Pension Plans', in Oxford Handbook of Pensions and Retirement Income

Cauley, Stephen Day, Pavlov, Andrey D. and Schwartz, Eduardo S., (2005) 'Homeownership as a Constraint on Asset Allocation', UCLA Anderson School of Management WP 10-05.

Cocco, João (2005) 'Portfolio choice in the presence of housing', Review of Financial Studies, 18(2), 535-567.

Damgaard, Anders, Brian Fuglsbjerg and Claus Munk (2003) 'Optimal Consumption and Investment Strategies with a Perishable and an Indivisible Durable Consumption Good', Journal of Economic Dynamics and Control, 28, 209-253

De Roon, Frans, Piet Eichholtz and Kees Koedijk (2002) 'The Portfolio Implications of Home Ownership', CEPR Discussion Paper n. 3501

Dimson, Elroy, Paul Marsh and Mike Staunton (2006) Global Investment Returns Yearbook, Rolf Elgeti, ABN-AMRO

Elton, Edwin J, and Martin J. Gruber (1992) 'Optimal Investment Strategies with Investor Liabilities', Journal of Banking and Finance, 16, 869-890

Flavin, Marjorie and Shinobu Nakagawa (2004) 'A Model of Housing in the Presence of Adjustment Costs: A Structural Interpretation of Habit Persistence', NBER WP 10458

Flavin, Marjorie and Takashi Yamashita (2002) 'Owner-Occupied Housing and the Composition of the Household Portfolio over the Life Cycle', American Economic Review, 92, 345-362 
Gibbons, M., S. Ross and J. Shanken (1989) 'A test of Efficiency for a Given Portfolio', Econometrica, 57, pp. 1121-1152

Goetzmann, William N., and Roger Ibbotson (1990) 'The Performance of Real Estate as an Asset Class.' Journal of Applied Corporate Finance, 3(1), pp. 65-76.

Goetzmann, William N. (1993) 'The Single Family Home in the Investment Portfolio.' Journal of Real Estate Finance and Economics, 6(3), pp. 201-22.

Grossman, Sanford J. and Guy Laroque (1990) 'Asset Pricing and Optimal Portfolio Choice in the Presence of Illiquid Durable Consumption Goods’, Econometrica, 58(1), pp. 25-51

Gourieroux, Christian and Francois Jouneau (1999) 'Econometrics of Efficient Fitted Portfolios', Journal of Empirical Finance, 6, pp. 78-118

Gourieroux; Christian and Alain Monfort (2003) 'Econometrics of Efficient Portfolios', CREST, mimeo

Guiso, Luigi, Michael Haliassos and Tullio Jappelli (2002) Household Portfolios, Cambridge: MIT Press.

Jobson J. D., and Robert Korkie (1982) 'Potential Performance and Tests of portfolio Efficiency', Journal of Financial Economics, 10, 433-466

Jorion, Philippe (1985) 'International Portfolio Diversification with Estimation Risk', Journal of Business, 58(3), 257-278

Markowitz , Harry (1952) 'Portfolio Selection', Journal of Finance, 7, 77-91

Mayers David (1973) 'Nonmarketable Assets and the Determination of Capital Asset Prices in the Absence of Riskless Asset', Journal of Business, 46(2), 258-267.

Merton, Robert C. (1969) 'Lifetime Portfolio Selection under Uncertainty: The Continuous-Time Case', Review of Economics and Statistics, 51, 247-257

Merton, Robert C. (1980) 'On Estimating the Expected Excess Return on the Market', Journal of Financial Economics, 8, 323-361.

Panetta, Fabio and Roberto Violi (1999) 'Is there an Equity Premium Puzzle in Italy? A Look at Asset Returns, Consumption and Financial Structure Data Over the Last Century', Banca d'Italia, Temi di discussione n. 353

Pelizzon, Loriana and Guglielmo Weber (2006) 'Are Household Portfolios Efficient? An Analysis Conditional on Housing', CEPR DP 3890, forthcoming Journal of Financial and Quantitative Analysis

Phelan, Michael (1995), 'Probability and Statistics Applied to the Practice of Financial Risk Management: The Case of JP Morgan's RiskMetrics”, Working Paper, Wharton School.

RiskMetrics (1999), Technical Document, JP Morgan, New York, USA

Ross, Stephen A. and Randall C. Zisler (1991) 'Risk and Return in Real Estate', Journal of Real Estate Finance and Economics, 4(2), 175-90.

Sinai, Todd and Nicholas S. Souleles (2005) "Owner-Occupied Housing as a Hedge Against Rent Risk", The Quarterly Journal of Economics, 120(2), 763-789.

Tobin, James (1958) 'Liquidity Preference as Behavior Towards Risk', Review of Economic Studies, 25, 65-87.

Yao, Rui and Harold H. Zhang (2005) 'Optimal Consumption and Portfolio Choices with Risky Housing and Borrowing Constraints', Review of Financial Studies, 18(1), 197-239 


\section{APPENDIX - A formal dynamic model}

In this appendix we present a formal model that can be used to justify equation (2). We take the view that consumers know how their housing needs evolve over time, and optimally choose whether to purchase or rent housing stock. Consumption of housing services may be lower or higher than the service flow of the housing stock owned: if it is lower, some services are rented, if higher, part of the housing stock is let to other consumers. The existence of a rental market allows consumption and investment motives to be separated, but the presence of housing needs implies that investment decisions are affected by current and future consumption of housing. In this context, we show how the optimal financial portfolio changes when the difference between housing needs and housing owned is non-zero, and how to assess whether observed household portfolios are indeed efficient.

We assume that consumers enjoy utility from non-durable consumption and from housing, and housing services can be obtained by either renting or owning a certain housing stock. We also assume that rent rates correlate with housing stock returns - we first consider the special case where there is unit correlation, then we explore the more general case with a positive, fixed correlation coefficient lower than 1 . The former case corresponds to a situation where owning is a perfect hedge (as in Yao and Zhang, 2005 and in Section 3 of this paper). The latter to the more general situation where house owning is not a prefect hedge against rent risk (as in Section 4.2 of this paper).

In our model, consumers do not live forever - the maximum length of life is $\mathrm{T}$ - but they can die in each period with a given, age-specific probability. Consumers care about their children, i.e. there is a bequest motive in their life-time utility function, but they wish to bequeath wealth, not housing. Housing can be bequeathed, but it is only valued for its monetary value, nothing else. Finally, housing needs evolve with age in a deterministic manner (that could be driven by demographic factors, like in Banks et al., 2004, or by an exogenously given income process). 
In the model, we make the strong assumption that housing consumption equals housing needs, that is housing consumption is an exogenously given function of age. Consumers can invest their wealth in a risk-free asset, that is an asset whose return is known in terms of the non-durable good, $n$ risky financial assets and housing stock. Housing services are provided by the housing stock that can be either rented or owned.

Formally, consumers maximize the following life-time expected utility index:

(1A) $E\left\{\int_{0}^{\tau} e^{-\delta t} u\left(C_{t}, h_{t}\right) d t+e^{-\delta \tau} B B\left(W_{\tau}\right) \mid G_{0}\right\}$

where $\tau$ is the stochastic end of life, $C_{t}$ is non-durable consumption, $h_{t}$ is consumption of housing services that relates to the housing stock owned $\left(H_{t}\right)$ or rented $\left(H_{t}^{R}\right)$ as follows:

(2A) $\quad h_{t}=\rho_{1} H_{t}+\rho_{2} H_{t}^{R}$

In the expressions above, $\delta$ is a time preference parameter, $\mathrm{u}($.$) is a well-behaved utility function$ and $B B$ is a bequest function depending on end-of-life wealth, $W_{\tau}$. Crucial to our analysis is the assumption that consumers do not wish to specifically bequeath housing stock - they only care about the money value of their bequests (if at all).

We assume that $h_{t}$ is not a choice variable for the consumer, but it changes deterministically with age (housing needs are hump-shaped). Consumers can choose their non-durable consumption, financial asset holdings and housing stock they own. $H_{t}^{R}$ is used to make up for the difference between necessary housing services and the housing services provided by owner-occupied housing ${ }^{6}$. In this model, wealth includes financial asset holdings, the present value of future earnings (human capital, that we shall assume to be risk-free), as well as the value of the housing stock owned net of

\footnotetext{
${ }^{6}$ Housing stock transactions may be subject to transaction costs, as in Grossman and Laroque (1990), Damgaard et al. (2003) and Cauley et al. (2005). We do not take them into account, nor do we make a distinction between deterministic housing needs and housing consumption, because needs are not observed.
} 
the present value of future housing needs. The way human capital (HC) and the present value of housing needs (V) are computed is explained in the sequel.

Formally, wealth at time $t$ is defined as:

(3A) $\quad W_{t}=P_{t} H_{t}+B_{t}+X_{t} \cdot 1-V_{t}+H C_{t}$

Human capital enters wealth for reasons explained in Bodie, Merton and Samuelson (1992). A similar argument applies to $V_{t}$, the present value of the future stochastic rents. In equation (3A), $B_{t}$ is the value of the risk-free asset position, $X_{t}$ is the row vector of the values held in the $n$ risky securities.

The prices of the housing stock $\left(P_{t}\right)$, of the $n$ risky financial securities $\left(S_{t}\right)$ and of the risk-free asset $\left(S_{0 t}\right)$ have the following dynamics:

$$
d P_{t}=\left(\mu_{H}+r_{f}\right) P_{t} d t+P_{t} d w_{H t} \text { with } d w_{H t}=\sigma_{P_{1}}^{T} d w_{1 t}+\sigma_{P_{2}} d w_{2 t}
$$

$$
d S_{t}=\operatorname{diag}\left\{S_{t}\right\}\left[\mu d t+\sigma d w_{1 t}\right] \text { with } S_{t} \in \mathfrak{R}^{n}
$$

$$
d S_{0 t}=r_{f} S_{0 t} d t
$$

where $w_{1 t}$ and $w_{2 t}$ are two independent Wiener processes.

The housing stock is assumed to have zero depreciation rate, and this implies that expected housing return $\mu_{H}$ must be defined as net of maintenance and repairs costs (as in Flavin and Yamashita, 2002).

Let us start from the present value of housing needs. We have to consider two stochastic processes: one for the consumer's death, another for the market price of housing needs. Thus we model a continuous time stochastic rent flow with stochastic expiration date.

We assume that the death process has a deterministic intensity rate (or survival rate). Let $\tau$ be an exponential random variable with intensity rate $\lambda_{t}$ and $N_{t}=I_{\tau \leq t}$ be the consumer death process. Let $\mathfrak{J}_{t}=\sigma\left(\pi_{s}, s \leq t\right), \quad H_{t}=\sigma\left(N_{s}, s \leq t\right)$ and finally $G_{t}=H_{t} \vee \mathfrak{I}_{t}$ with $H_{t}$ independent of $\mathfrak{J}_{t}$. 
Assume that the intensity is a deterministic function of time $\lambda_{t}=\lambda(t)$ and that at each instant the consumer pays a rent flow $\pi_{t} h_{t}$, where $\pi_{t}$ represents the rental value (per square meter) and $h_{t}$ housing consumption (in square meters). In view of the evidence that rents and house prices are strongly related, we follow Yao and Zhang (2005) and further assume $\pi_{t}$ to be proportional to the house price: $\pi_{t}=\alpha P_{t}$, thus:
$d \pi_{t}=\pi_{t}\left(\mu_{H}+r_{f}\right) d t+\pi_{t} d w_{H t}$,
with $\pi_{0}=\alpha P_{0}^{7}$

We write the following dynamics for the intensity rate and housing needs:
(8A) $d \lambda_{t}=-\lambda_{t} g(a(t)) d t$
$\lambda_{0}$ given
(9A) $d h_{t}=-h_{t} f(a(t)) d t$
$h_{0}$ given

where $a(t)$ is a known age function (for instance, a polynomial in age).

The expected present value of the future rent stochastic flow is for the replicability argument (see Bodie, Merton and Samuelson, 1992, for a similar argument on human capital):

(10A) $V_{t}=E\left\{\int_{t}^{\tau} e^{-\left(\mu_{H}+r_{f}\right)(s-t)} \pi_{s} h_{s} d s \mid G_{t}\right\}=I_{\tau>t} \alpha P_{t} h_{t} Q_{t}$

where:

(11A) $Q_{t}=\int_{t}^{T} e^{-\int_{t}^{s} g(a(u))+f(a(u))_{v} d u} d s$

This present value can be subtracted from the housing value in the definition of wealth because of unit correlation between housing prices and rent. (We discuss in the Appendix the case where the correlation is lower than one).

Note that the dynamics of the present value is a martingale process obtained as localization of a function of the house price process. In particular the dynamics is:

\footnotetext{
${ }^{7}$ An extension to the case where rents and house prices have less than unit correlation is presented in the Appendix.
} 
(12A) $d V_{t}=V_{t}\left(\mu_{H}+r_{f}-f(a(t))+\frac{\partial Q_{t}}{\partial t} \frac{1}{Q_{t}}\right) d t+V_{t} d w_{H t}$

which is a geometrical Brownian motion with a non-constant drift.

For human capital the computations are similar in principle, under the (simplifying) assumption that labor income risk can be fully insured. Human capital is defined as the present value of future earnings prior to retirement and of future pension payments after retirement, where the discount rate is the risk-free rate. We assume that future earnings follow a deterministic age profile, and that retirement age and the replacement rate are known to the individual. Death is instead not known, but follows the same stochastic process as above. Under these assumptions, the relevant discount rate is the risk-free rate.

Let $X_{t}^{T}=\theta_{t}^{T} \operatorname{diag}\left\{S_{t}\right\}$ be the vector of total amounts invested in each financial asset and assume the self-financing portfolio hypothesis holds:

(13A) $d X_{t}=\sum_{i=0}^{n} \theta_{i t} d S_{i t}$

then the wealth process has the following dynamic:

$$
\begin{aligned}
d W_{t} & =\left(r_{f} W_{t}-V_{t}\left(\mu_{H}-f(a(t))+\frac{\partial Q_{t}}{\partial t} \frac{1}{Q_{t}}\right)+X_{t} \cdot\left(\mu^{T}-r_{f} \cdot 1\right)-C_{t}+P_{t} H_{t} \mu_{H}\right) d t \\
& +X_{t} \cdot \sigma d w_{1 t}+P_{t} H_{t} d w_{H t}-V_{t} d w_{H t}
\end{aligned}
$$

The value function of the problem is:

$$
J=\sup _{\{\theta, H, C\}} E\left\{\int_{0}^{\tau} e^{-\delta t} u\left(C_{t}, h_{t}\right) d t+e^{-\delta \tau} u\left(W_{\tau}\right) \mid G_{0}\right\}
$$

and the Hamilton-Jacobi-Bellman equation associated to the value function is:

$$
(16 \mathrm{~A})(\delta+\lambda) J=\sup _{\{\theta, H, C\}} E\left\{u(h, C)+\frac{\partial J}{\partial W} d W_{t}+\frac{1}{2} \frac{\partial^{2} J}{\partial W^{2}} d W_{t}^{2}+\frac{\partial J}{\partial P} d P_{t}+\frac{1}{2} \frac{\partial^{2} J}{\partial P^{2}} d P_{t}^{2}+\frac{\partial^{2} J}{\partial W \partial P} d P_{t} d W_{t}\right\}
$$

which becomes, under the previous assumptions on the wealth process dynamics in (14A): 
(17A) $(\delta+\lambda) J=\sup _{\{\theta, h, c\}}\left\{\frac{\partial J}{\partial W}\left(r_{f} W_{t}-Q_{t} h_{t} \alpha P_{t}\left(\mu_{H}+f(a(t))-\frac{\partial Q_{t}}{\partial t} \frac{1}{Q_{t}}\right)+X_{t} \cdot\left(\mu^{T}-r_{f} \cdot 1\right)-C_{t}+P_{t} H_{t} \mu_{H}\right)\right.$

$$
\begin{aligned}
& +\frac{1}{2} \frac{\partial^{2} J}{\partial W^{2}}\left(X_{t} \sigma \sigma^{\mathrm{T}} X_{t}^{T}+\left(P_{t}\left(H_{t}-\alpha h_{t} Q_{t}\right)\right)^{2}\left[\sigma_{P_{2}}^{2}+\sigma_{P_{1}} \sigma_{P_{1}}^{T}\right]+2 P_{t}\left(H_{t}-\alpha h_{t} Q_{t}\right) X_{t} \cdot \sigma \sigma_{P_{1}}^{T}\right)+ \\
& \left.+\frac{\partial J}{\partial P} P_{t}\left(\mu_{H}+r_{f}\right)+\frac{1}{2} \frac{\partial^{2} J}{\partial P^{2}} P_{t}^{2}\left[\sigma_{P_{2}}^{2}+\sigma_{P_{1}} \sigma_{P_{1}}^{T}\right]+\frac{\partial^{2} J}{\partial W \partial P}\left(P_{t}^{2}\left(H_{t}-\alpha h_{t} Q_{t}\right)\left[\sigma_{P_{2}}^{2}+\sigma_{P_{1}} \sigma_{P_{1}}^{T}\right]+X_{t} P_{t} \cdot \sigma \sigma_{P_{1}}^{T}\right)\right\}
\end{aligned}
$$

and taking first order conditions with respect to $\{C, \theta, H\}$ respectively, we obtain:

(18A) $\frac{\partial u}{\partial C}-\frac{\partial J}{\partial W}=0$

(19A) $\frac{\partial J}{\partial W}\left(\mu^{T}-r_{f} \cdot 1\right)+\frac{\partial^{2} J}{\partial W^{2}}\left(\sigma \sigma^{\mathrm{T}} X_{t}^{T}+P_{t}\left(H_{t}-\alpha h_{t} Q_{t}\right) \sigma \sigma_{P_{1}}^{T}\right)+\frac{\partial^{2} J}{\partial W \partial P}\left(P_{t} \cdot \sigma \sigma_{P_{1}}^{T}\right)=0$

(20A) $\frac{\partial J}{\partial W} P_{t} \mu_{H}+\frac{\partial^{2} J}{\partial W^{2}}\left(P_{t}^{2}\left(H_{t}-\alpha h_{t} Q_{t}\right)\left[\sigma_{P_{2}}^{2}+\sigma_{P_{1}} \sigma_{P_{1}}^{T}\right]+P_{t} X_{t} \cdot \sigma \sigma_{P_{1}}^{T}\right)+\frac{\partial^{2} J}{\partial W \partial P} P_{t}^{2}\left[\sigma_{P_{2}}^{2}+\sigma_{P_{1}} \sigma_{P_{1}}^{T}\right]=0$

Then focusing on the optimal portfolio choice, using the second block of first order conditions (19A) we derive:

(21A) $X_{t}^{T}=-\left(\sigma \sigma^{\mathrm{T}}\right)^{-1} \frac{\frac{\partial J}{\partial W}\left(\mu^{T}-r_{f} \cdot 1\right)}{\frac{\partial^{2} J}{\partial W^{2}}}-P_{t}\left(H_{t}-\alpha h_{t} Q_{t}\right)\left(\sigma^{\mathrm{T}}\right)^{-1} \sigma_{P_{1}}^{T}-\frac{\frac{\partial^{2} J}{\partial W \partial P}}{\frac{\partial^{2} J}{\partial W^{2}}}\left(P_{t} \cdot\left(\sigma^{T}\right)^{-1} \sigma_{P_{1}}^{T}\right)$

where the first term is the standard Markowitz portfolio, the second term is a hedge term for the net position in housing (housing stock owned net of the present value of future rents) and the third term captures the income and substitution effects of changes in the relative price of housing. We can show that the state variable $P$ does not affect the marginal value function of wealth (that is: $\frac{\partial^{2} J}{\partial W \partial P}=0$ ) when the utility function is additive separable in $\mathrm{C}$ and $\mathrm{H}$ (this extends Damgaard et al, 2004). Under these conditions, the standard equation (2) holds.

The third block of first order conditions (equation (20A)) can be simplified if we recall that the derivative of housing consumption with respect to the housing stock owned is zero. Re-arranging terms, and substituting for $\mathrm{X}$ from (21A), we derive the following relation: 
(22A) $P_{t} H_{t}=-\frac{\frac{\partial J}{\partial W}}{\frac{\partial^{2} J}{\partial W^{2}} \sigma_{P_{2}}^{2}}\left[\mu_{H}+\left(\mu-r_{f} \cdot 1^{T}\right)\left(\sigma \sigma^{T}\right)^{-1} \sigma \sigma_{P_{1}}^{T}\right]+P_{t} \alpha h_{t} Q$

for the case where $\frac{\partial^{2} J}{\partial W \partial P}=0$.

Equation (21A) has been derived without using the first order condition for the housing, and is therefore useful to analyze portfolio holdings even if we believe short run housing stock adjustments to be costly. Equation (22A) instead explicitly uses the optimality condition for $\mathrm{H}_{\mathrm{t}}$, and is best seen as suggestive of what consumers should try and do in the case where transaction costs are important. Equation (22A) shows that the optimal housing stock is the larger, the higher the present value of future rents: house-owning does indeed play the role of a hedge against rent risk, as suggested by Sinai and Souleles (2005). Our model can be used to justify why home-ownership is so wide-spread, and housing wealth is so important in household portfolios.

How does the analysis change when house prices are more volatile than rents, and the two processes have positive, but less than unitary correlation? To answer this question, we extend the model presented above to the general case of an arbitrary, fixed correlation coefficient between rent rates and housing stock returns.

Let equation (4A) be replaced by:

$$
d P_{t}=\left(\mu_{H}+r_{f}\right) P_{t} d t+P_{t} d w_{H t} \text { with } d w_{H t}=\sigma_{P 1}^{T} d w_{1 t}+\sigma_{P 2} d w_{2 t}+\sigma_{P 3} d w_{3 t}
$$

and assume the equation for the rental value dynamics is instead given by:

$$
d \pi_{t}=\left(\mu_{\pi}+r_{f}\right) \pi_{t} d t+\pi_{t} d w_{\pi t} \text { with } d w_{\pi t}=\sigma_{P 1}^{T} d w_{1 t}+\sigma_{P 2} d w_{2 t}
$$

where $\pi_{t}=\alpha P_{t}$, but proportionality does not hold in any other period and $w_{1 t}, w_{2 t}$ and $w_{3 t}$ are independent Wiener processes.

The standard deviation of the rental price process is:

(25A) $\sigma_{\pi}=\sqrt{\left[\sigma_{P 1} ; \sigma_{P 2}\right]^{T} *\left[\sigma_{P 1} ; \sigma_{P 2}\right]}$ 
the standard deviation of the house price process is instead given by:

(26A) $\sigma_{H}=\left(\sigma_{\pi}^{2}+\sigma_{P 3}^{2}\right)^{1 / 2}$

The covariance of these two processes is given by $\sigma_{\pi}^{2}$ and the slope coefficient of the regression of rental price changes on house price changes is:

(27A) $\beta_{P \pi}=\frac{\sigma_{\pi}^{2}}{\sigma_{H}^{2}} \quad$ and $\quad 0 \leq \beta_{P \pi} \leq 1$

It is easily checked that $\beta_{P \pi}$ is the square of the correlation coefficient.

Let us assume for simplicity that $\mu_{\pi}=\beta_{P \pi} \mu_{H}$. In this context, owning housing stock provides a hedge against rent risk, but not a perfect hedge. Standard results on optimization by risk averse investors imply that households will reduce this type of large, undiversifiable risk by purchasing housing stock, even though not for the full amount of their present value of housing needs.

We assume that the $n$ risky financial securities $\left(S_{t}\right)$ and of the risk-free asset $\left(S_{0 t}\right)$ have the same dynamics as in (5A) and (6A) and that the intensity rate and housing needs have the same dynamics as in $(8 \mathrm{~A})$ and $(9 \mathrm{~A})$.

In line with Bodie et al (1992), bya replicability argument, in order to hedge the risk in $\pi_{s} h_{s}$ (for any s $>0$ ) the household should have $\pi_{t} h_{s} \beta_{P \pi}$ in housing. This should hold for all future periods.

The present value of the future rent stochastic flow that should be hedged is:

(28A) $V_{t}^{\beta}=E\left\{\int_{t}^{\tau} e^{-\left(r_{f}+\beta_{P \pi} \mu_{H}\right)(s-t)} \pi_{s} h_{s} \beta_{P \pi} d s \mid G_{t}\right\}=I_{\tau>t} \alpha P_{t} h_{t} \beta_{P \pi} Q_{t}$

Note that the dynamics of the present value is a martingale process obtained as localization of a function of the house price process. In particular the dynamics is:

(29A) $d V_{t}^{\beta}=V_{t}^{\beta}\left(r_{f}+\beta_{P \pi} \mu_{H}-f(a(t))+\frac{\partial Q_{t}}{\partial t} \frac{1}{Q_{t}}\right) d t+V_{t}^{\beta} d w_{H t}$

which is a geometric Brownian motion with a non-constant drift.

In this context, wealth at time $\mathrm{t}$ is defined as:

(30A) $W_{t}=P_{t} H_{t}+B_{t}+X_{t} \cdot 1-V^{\beta}{ }_{t}+H C_{t}$ 
where $V_{t}^{\beta}$ represents the expected present value of current and future stochastic rents that are hedged, and $B_{t}$ is the value of the risk-free asset position, $X_{t}$ is the row vector of the values held in the $\mathrm{n}$ risky securities as before.

Then the wealth process has the following dynamics:

$$
\text { (31A) } \begin{aligned}
d W_{t} & =\left(r_{f} W_{t}-V_{t}\left(r_{f}+\beta_{P \pi} \mu_{H}-f(a(t))+\frac{\partial Q_{t}}{\partial t} \frac{1}{Q_{t}}\right)+X_{t}^{T} \cdot\left(\mu-r_{f} \cdot 1\right)-C_{t}+P_{t} H_{t} \mu_{H}\right) d t \\
& +X_{t} \cdot \sigma d w_{1 t}+P_{t} H_{t} d w_{H t}-V_{t} d w_{H t}-\pi_{t} h_{t} d w_{\pi t}+\alpha P_{t} \beta_{P \pi} h_{t} d w_{H t}
\end{aligned}
$$

The value function of the problem is:

$$
J=\sup _{\{\theta, H, C\}} E\left\{\int_{0}^{\tau} e^{-\delta t} u\left(C_{t}, h_{t}\right) d t+e^{-\delta \tau} u\left(W_{\tau}\right) \mid G_{0}\right\}
$$

and the Hamilton-Jacobi-Bellman equation associated to the value function is:

$$
\begin{aligned}
& (\delta+\lambda) J=\sup _{\{\theta, H, C\}} E\left\{u(C, h)+\frac{\partial J}{\partial W} d W_{t}+\frac{1}{2} \frac{\partial^{2} J}{\partial W^{2}} d W_{t}^{2}+\frac{\partial J}{\partial P} d P_{t}+\frac{1}{2} \frac{\partial^{2} J}{\partial P^{2}} d P_{t}^{2}-\frac{\partial J}{\partial \pi} d \pi_{t t}^{2}\right. \\
& \left.+\frac{1}{2} \frac{\partial^{2} J}{\partial \pi^{2}} d \pi+\frac{\partial^{2} J}{\partial W \partial P} d P_{t} d W_{t}-\frac{\partial^{2} J}{\partial W \partial \pi} d \pi_{t} d W_{t}-\frac{\partial^{2} J}{\partial \pi \partial P} d P_{t} d \pi_{t}\right\}
\end{aligned}
$$

which becomes, under the previous assumptions on the wealth process dynamics in $(31 \mathrm{~A})$ :

$$
\begin{aligned}
(34 \mathrm{~A}) 0= & -(\delta+\lambda) J+\sup _{\{\theta, H, C\}}\left\{\frac { \partial J } { \partial W } \left(r_{f} W_{t}-Q_{t} \beta_{P_{\pi}} h_{t} \alpha P_{t}\left(\mu_{H}+f(a(t))-\frac{\partial Q_{t}}{\partial t} \frac{1}{Q_{t}}\right)\right.\right. \\
& \left.+X_{t} \cdot\left(\mu^{T}-r_{f} \cdot 1\right)-C_{t}+P_{t} H_{t} \mu_{H}-\mu_{H} h_{t}\left(\pi_{t}-\alpha P_{t} \beta_{P \pi}\right)\right) \\
& +\frac{1}{2} \frac{\partial^{2} J}{\partial W^{2}}\left(X_{t} \sigma \sigma^{\mathrm{T}} X_{t}^{T}+\left(P_{t}\left(H_{t}-\alpha h_{t} \beta_{P_{\pi}}\left(Q_{t}-1\right)\right)\right)^{2}\left[\sigma_{P_{3}}^{2}+\sigma_{P_{2}}^{2}+\sigma_{P_{1}} \sigma_{P_{1}}^{T}\right]\right. \\
& \left.+\left(\pi h_{t}\right)^{2}\left[\sigma_{P_{2}}^{2}+\sigma_{P_{1}} \sigma_{P_{1}}^{T}\right]+2 P_{t}\left(H_{t}-\alpha h_{t} \beta_{P_{\pi}}\left(Q_{t}-1\right)\right) X_{t} \cdot \sigma \sigma_{P_{1}}^{T}-2 \pi_{t} h_{t} X_{t} \cdot \sigma \sigma_{P_{1}}^{T}\right) \\
& +\frac{\partial J}{\partial P} P_{t}\left(\mu_{H}+r_{f}\right)+\frac{1}{2} \frac{\partial^{2} J}{\partial P^{2}} P_{t}^{2}\left[\sigma_{P_{2}}^{2}+\sigma_{P_{1}} \sigma_{P_{1}}^{T}\right] \\
& +\frac{\partial^{2} J}{\partial W \partial P}\left(P_{t}^{2}\left(H_{t}-\alpha h_{t} \beta_{P \pi}(Q-1)\left[\sigma_{P_{3}}^{2}+\sigma_{P_{2}}^{2}+\sigma_{P_{1}} \sigma_{P_{1}}^{T}\right]+X_{t} P_{t} \cdot \sigma \sigma_{P_{1}}^{T}\right)\right.
\end{aligned}
$$




$$
\begin{aligned}
& -\frac{\partial J}{\partial \pi} \pi_{t}\left(\mu_{\pi}+r_{f}\right)+\frac{1}{2} \frac{\partial^{2} J}{\partial \pi^{2}} \pi_{t}^{2}\left[\sigma_{P_{2}}^{2}+\sigma_{P_{1}} \sigma_{P_{1}}^{T}\right] \\
& -\frac{\partial^{2} J}{\partial W \partial \pi}\left(\left(\pi h_{t}\right)^{2}\left[\sigma_{P_{2}}^{2}+\sigma_{P_{1}} \sigma_{P_{1}}^{T}\right]+X_{t} \pi_{t} \cdot \sigma \sigma_{P_{1}}^{T}+\left(P_{t} H_{t}-V_{t}\right) \pi_{t} \sigma_{\pi}^{2}\right)-\frac{\partial^{2} J}{\partial P \partial \pi}\left(\pi_{t} P_{t}\left[\sigma_{\pi}^{2}\right]\right)
\end{aligned}
$$

and taking first order conditions with respect to $\{C, \theta, H\}$ respectively, we obtain:

(35A) $\frac{\partial u}{\partial C}-\frac{\partial J}{\partial W}=0$

(36A) $\frac{\partial J}{\partial W}\left(\mu^{T}-r_{f} \cdot 1\right)+\frac{\partial^{2} J}{\partial W^{2}}\left(\sigma \sigma^{\mathrm{T}} X_{t}^{T}+\left(P_{t}\left(H_{t}-\alpha h_{t} \beta_{P \pi}\left(Q_{t}-1\right)-\alpha h_{t}\right)\right) \sigma \sigma_{P_{1}}^{T}\right)$

$$
+\frac{\partial^{2} J}{\partial W \partial P}\left(P_{t} \cdot \sigma \sigma_{P_{1}}^{T}\right)-\frac{\partial^{2} J}{\partial W \partial \pi} \pi_{t}\left[\sigma \sigma_{P_{1}}^{T}\right]=0
$$

(37A) $\frac{\partial J}{\partial W} P_{t} \mu_{H}+\frac{\partial^{2} J}{\partial W^{2}}\left(P_{t}^{2}\left(H_{t}-\alpha h_{t} \beta_{P \pi}\left(Q_{t}-1\right)\right)\left[\sigma_{P_{3}}^{2}+\sigma_{P_{2}}^{2}+\sigma_{P_{1}} \sigma_{P_{1}}^{T}\right]+P_{t} X_{t} \cdot \sigma \sigma_{P_{1}}^{T}\right)+$

$$
\frac{\partial^{2} J}{\partial W \partial P} P_{t}^{2}\left[\sigma_{P_{3}}^{2}+\sigma_{P_{2}}^{2}+\sigma_{P_{1}} \sigma_{P_{1}}^{T}\right]-\frac{\partial^{2} J}{\partial W \partial \pi} P_{t} \pi_{t}\left[\sigma_{\pi}^{2}\right]=0
$$

Then focusing on the optimal portfolio choice, using the second block of first order conditions (36A) we derive:

$$
\text { (38A) } \begin{aligned}
X_{t}^{T} & =-\left(\sigma \sigma^{\mathrm{T}}\right)^{-1} \frac{\frac{\partial J}{\partial W}\left(\mu^{T}-r_{f} \cdot 1\right)}{\frac{\partial^{2} J}{\partial W^{2}}}-\left(P_{t}\left(H_{t}-\alpha h_{t} \beta_{P \pi}\left(Q_{t}-1\right)-\alpha h_{t}\right)\right)\left(\sigma^{\mathrm{T}}\right)^{-1} \sigma_{P_{1}}^{T} \\
& -\left[\frac{\frac{\partial^{2} J}{\partial W \partial P}}{\frac{\partial^{2} J}{\partial W^{2}}}\left(P_{t} \cdot\left(\sigma^{T}\right)^{-1} \sigma_{P_{1}}^{T}\right)-\frac{\frac{\partial^{2} J}{\partial W \partial \pi}}{\frac{\partial^{2} J}{\partial W^{2}}}\left(\pi_{t} \cdot\left(\sigma^{T}\right)^{-1} \sigma_{P_{1}}^{T}\right)\right]
\end{aligned}
$$

where the first term is the standard Markowitz portfolio, the second term is a hedge term for the net position in housing (housing stock owned net of the present value of future rents that are hedged by purchasing housing stock) and the third term captures the income and substitution effects of changes in the relative price of housing. We can show that the state variables $P$ and $\pi$ do not affect 
the marginal value function of wealth (that is: $\frac{\partial^{2} J}{\partial W \partial P}=0$ and $\frac{\partial^{2} J}{\partial W \partial \pi}=0$ ) when the utility function is additive separable in $\mathrm{C}$ and $\mathrm{H}$ (this extends Damgaard et al., 2004). With this last assumption equation (38A) collapses to equation (21A) when $\sigma_{\pi}^{2}=\sigma_{H}^{2}$ (i.e. $\beta_{P \pi}=1$ ). The robustness analysis performed in Section 4.2 is based on this general case, where $\beta_{P \pi}$ is allowed to vary from zero to one. 